\title{
A Statistical Adjustment of Regional Climate Model Outputs to Local Scales: Application to Platja de Palma, Spain
}

\author{
A. Amengual \\ Grup de Meteorologia, Departament de Física, Universitat de les Illes Balears, and Departament de Recerca en Canvi Global, \\ Institut Mediterrani d'Estudis Avançats, Palma de Mallorca, Spain \\ V. HOMAR AND R. ROMERO \\ Grup de Meteorologia, Departament de Física, Universitat de les Illes Balears, Palma de Mallorca, Spain

\section{S. AlONSO} \\ Grup de Meteorologia, Departament de Física, Universitat de les Illes Balears, and Departament de Recerca en Canvi Global, \\ Institut Mediterrani d'Estudis Avançats, Palma de Mallorca, Spain

\section{RAMIS}

Grup de Meteorologia, Departament de Física, Universitat de les Illes Balears, Palma de Mallorca, Spain

(Manuscript received 21 December 2010, in final form 29 July 2011)

\begin{abstract}
Projections of climate change effects for the System of Platja de Palma (SPdP) are derived using a novel statistical technique. Socioeconomic activities developed in this settlement are very closely linked to its climate. Any planning for socioeconomic opportunities in the mid- and long term must take into account the possible effects of climate change. To this aim, daily observed series of minimum and maximum temperatures, precipitation, relative humidity, cloud cover, and wind speed have been analyzed. For the climate projections, daily data generated by an ensemble of regional climate models (RCMs) have been used. To properly use RCM data at local scale, a quantile-quantile adjustment has been applied to the simulated regional projections. The method is based on detecting changes in the cumulative distribution functions between the recent past and successive time slices of the simulated climate and applying these, after calibration, to the recent past (observed) series. Results show an overall improvement in reproducing the present climate baseline when using calibrated series instead of raw RCM outputs, although the correction does not result in such clear improvement when dealing with very extreme rainfalls. Next, the corrected series are analyzed to quantify the climate change signal. An increase of the annual means for temperatures together with a decrease for the remaining variables is projected throughout the twenty-first century. Increases in weak and intense daily rainfalls and in high extremes for daily maximum temperature can also be expected. With this information at hand, the experts planning the future of SPdP can respond more effectively to the problem of local adaptation to climate change.
\end{abstract}

\section{Introduction}

Observations show that the global mean surface temperature has increased notably during the twentieth century. In fact, the second half of the twentieth century

Corresponding author address: Arnau Amengual, Dept. de Física, Universitat de les Illes Balears, Edifici Mateu Orfila, Cra. de Valldemossa, km. 7.5, 07122 Palma de Mallorca, Spain.

E-mail: arnau.amengual@uib.es has been the warmest period for at least the last $1300 \mathrm{yr}$ in the Northern Hemisphere (Solomon et al. 2007). According to the National Oceanic and Atmospheric Administration (NOAA)'s National Climatic Data Center (Smith et al. 2008), the 14 warmest years in the instrumental record have been observed during the 1995-2009 period. The rate of global surface warming from 1979 to 2005 is estimated at $0.27^{\circ} \mathrm{C}$ decade $^{-1}$. Furthermore, the estimated trends at regional scale for this interval show high spatial variability and, for the 
Mediterranean area as a whole, the Intergovernmental Panel on Climate Change (IPCC) shows this trend is between 0.25 and $0.35^{\circ} \mathrm{C} \mathrm{decade}{ }^{-1}$ (Solomon et al. 2007). Associated with this global warming, a redistribution of the rainfall and other atmospheric variables (e.g., pressure, wind, cloudiness) has been observed with even higher spatial variability than for temperature. For the whole Mediterranean region, observations indicate a decrease in the precipitation amounts estimated between $5 \%$ and $20 \%$ from 1901 to 2005 . This reduction has appeared with decreases below 3\% during the 1979-2005 period (Solomon et al. 2007). However, the robust detection of precipitation trends is always problematic owing to their high spatial and temporal variability (Huntington 2006).

The study of climate change from instrumental records aggregated in databases of regional range-for example, the Mediterranean Basin - can inevitably mask local features. Being aware of this problem, Homar et al. (2010) carried out a study of the recent trends in rainfall and temperatures for the Balearic Islands. The results of their study indicate a decrease in annual rainfall amounts at a rate of $16.6 \mathrm{~mm}$ decade ${ }^{-1}$ for the second half of the twentieth century. Autumn and winter decreases are responsible for most of the decline in precipitation. The extreme of daily precipitation - that is, either the smallest or largest values-are becoming more frequent together with a decreasing contribution of the intermediate amounts to the total accumulations. Furthermore, the study reveals that minimum and maximum temperatures over the last decades of the twentieth century have risen at a rate of $0.51^{\circ}$ and $0.48^{\circ} \mathrm{C} \mathrm{decade}{ }^{-1}$, respectively. This regional warming is most evident for springs and summers.

The Consortium of Platja de Palma - an agreement signed by the Balearic Islands' government and the Ministry of Industry, Tourism and Trade of the Spanish government for the redesign and suitability to the needs of the twenty-first century of this important tourist resortwas set up with the aim of restructuring the tourist industry for the System of Platja de Palma (SPdP). This emplacement is one of the major resorts in the whole Mediterranean region, and it is entirely devoted to a mass tourism model (Fig. 1; further information at http:// consorcioplayadepalma.es). The consortium has geared its work toward configuring a different vision and contemplating a new tourist model suitable to the needs of the twenty-first century. Major guidelines for the consortium include as key issues sustainability, climate and global change, and social and residential cohesion. Therefore, the assessment of the consequences of climate change and the subsequent implementation of adaptation strategies has become one of its main concerns. Within this framework, we explore future climate projections, and specifically, the projected changes of the most relevant meteorological parameters for carrying out suitable sun, sea, and sand (3S) leisure activities. Specifically, we explore the shifts in the future annual and seasonal mean regimes as well as the changes in the extreme climatic events. Both topics have a high social and economic interest, since the productive enterprise developed in tourist regions are strongly linked to its climatology, being extremely sensitive to extreme weather impacts as well (Amelung and Viner 2006).

Atmosphere-ocean general circulation models (AOGCMs) constitute the primary tool to produce future climate projections. AOGCM simulations have been run under a wide range of scenarios for greenhouse gas emissions and aerosols [Special Report on Emissions Scenarios (SRES); Nakicenovic et al. 2000). These scenarios describe plausible evolutions for these emissions depending on socioeconomic conditions and world development guidelines. The A1B scenario has widely been adopted in the latest climatic simulations, since it is halfway between the most unfavorable (A2) and optimistic (B1) scenarios (see http://www.iiasa.ac.at/web-apps/tnt/RcpDb/dsd? Action $=$ htmlpage $\&$ page $=$ welcome $).{ }^{1}$ Although these models are suitable to provide future global climate scenarios, their coarse spatial resolutions are not appropriate to evaluate most regional and local impact studies. Although climate change is a problem of global causes and consequences, its impacts become apparent locally. Climate change analysis at regional and local scales, such as an increase in the frequency and/or intensity of extreme events, requires quantitative estimations at increased spatial and temporal resolutions.

Dynamical downscaling applied to AOGCM outputs attempts to account for the effects of mesoscale forcings and other subgrid-scale features by nesting increasedresolution regional climate models (RCMs) in large-scale meteorological fields generated by general models (Giorgi and Mearns 1999; Denis et al. 2002; Beck et al. 2004). For the western Mediterranean area, regional effects exert a particularly strong influence on the distribution of meteorological variables owing to the characteristic configuration of land and sea and complex orography (Fig. 1; Amengual et al. 2007). Although regional climate modeling often improves the performance from AOGCMs at regional scales, the resolution still remains inadequate to address uncertainties arising from several sources. We present a new statistical approach based on the application of a quantile-quantile $(\mathrm{Q}-\mathrm{Q})$ adjustment to several projections of RCMs to better assess climate change impacts over the SPdP. Simulated daily data have been

\footnotetext{
${ }^{1}$ Note that the global climate modeling community is currently using the representative concentration pathway (RCP) scenarios.
} 


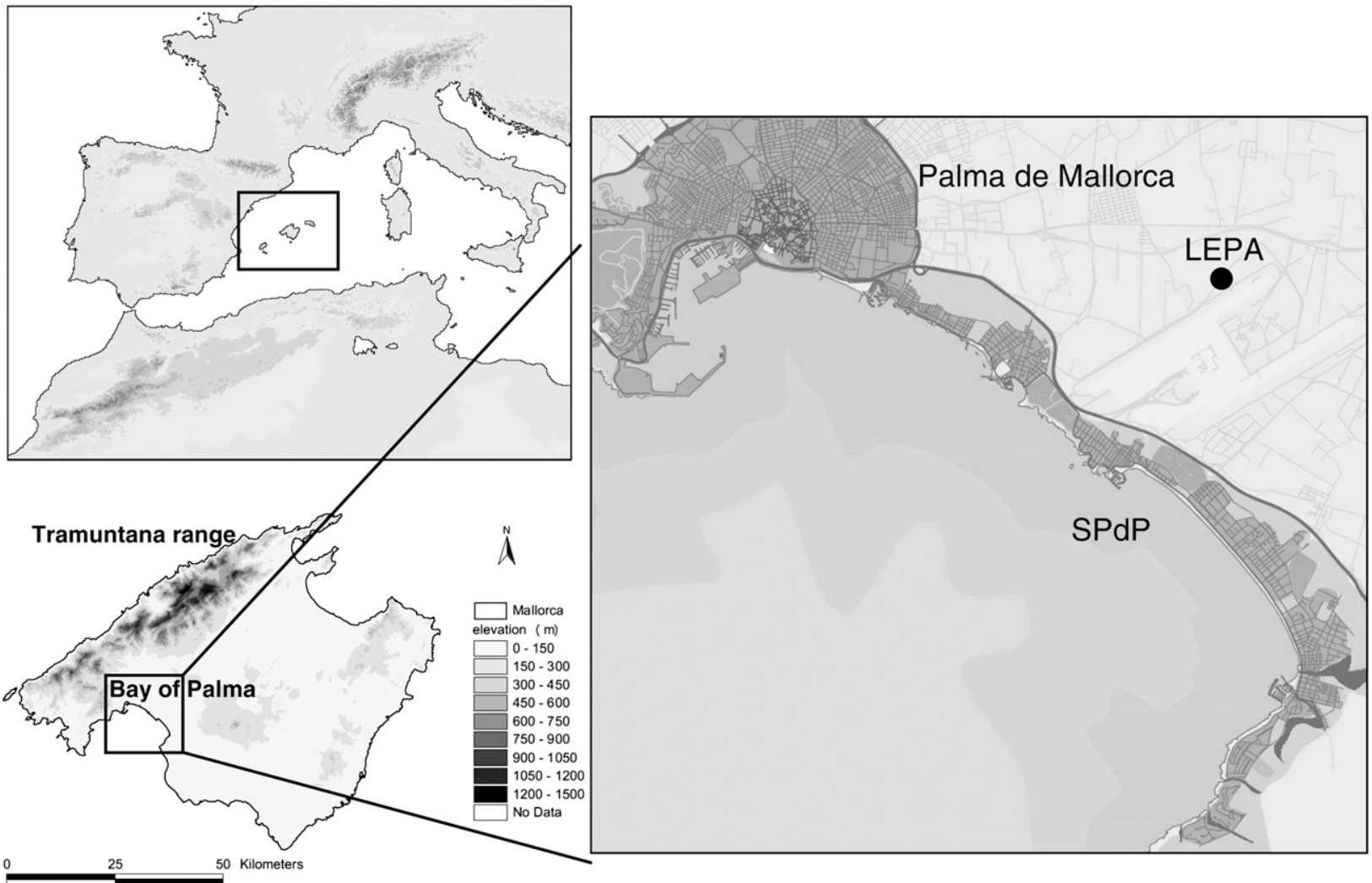

FIG. 1. Geographical location for the SPdP in the western Mediterranean region. Major topographic features for the entire area and Mallorca Island are shown. Also displayed is the location of the automatic weather station (LEPA).

provided by a set of regional climate models run under the A1B emissions scenario.

The rest of the paper is structured as follows: section 2 contains a brief description of the study area, addressing the main environmental, social, and economic issues; section 3 describes the observed and simulated databases that have been used, as well as the proposed empirical correction method and it presents the results of a validation test applied to this adjustment technique; section 4 discusses the projected annual and seasonal variations of the mean and extreme regimes for the parameters of interest; and finally, section 5 provides an assessment of the implemented approach and its later applications.

\section{Overview of the study area: Climatic characteristics and economic activities}

The climate of the Balearic Islands is characteristic of the western Mediterranean region. It is associated with a wide range of synoptic flows and is strongly influenced by the Mediterranean Sea, which is the main source of moisture for the region. In summertime, the Azores's high pressure system dominates the synoptic situation, producing a sustained increase of the air and sea surface temperatures together with a period of reduced precipitation. When the eastward extension of the Azores high pressure system moves equatorward in early autumn, it facilitates the arrival of mid- to upper-level Atlantic cold air masses. Given the presence of moist and warm Mediterranean air at low levels in autumn, relatively high sea surface temperatures, and the complex orography of the region, this is when heavy rainfalls are most common (Tudurí and Ramis 1997; Romero et al. 1999; Amengual et al. 2008).

The northern side of Mallorca can be affected by intense northerly to westerly flows linked to the passage of midlatitude fronts, mostly in winter. This area also has the largest number of days in Mallorca with strong winds, cloudiness, and rain (the mean annual precipitation amounts are about $600-700 \mathrm{~mm}$ ). In contrast, moist easterly flows produce most of the rainy days (typically convective in character) in the southern part of the island, which can result in very high precipitation rates, principally in autumn, but with occasional events in spring and winter (Romero et al. 1999).

Furthermore, Mallorca constitutes a perfect example of a region with complex topography. The island is characterized by an irregular distribution of mountainous ranges 
and plains. The highest elevations are in the northwestern mountainous region-the Tramuntana range-with elevations close to $1500 \mathrm{~m}$ (Fig. 1). Mallorca's rugged relief together with an irregular coastline and its inherent insular characteristics (e.g., evident in the summer seabreeze regimes) result in large climatological diversity (Guijarro 1986). For example, mean annual rainfall amounts in the Serra de Tramuntana can range from 1000 to $1500 \mathrm{~mm}$, whereas in the southern coastline only $50 \mathrm{~km}$ away the amounts barely exceed $350 \mathrm{~mm}$. For the Balearics, the mean annual rainfall amount is roughly $560 \mathrm{~mm}$ (Homar et al. 2010). Also, temperatures strongly depend on elevation and distance from the sea. Likewise, the western Mediterranean area is quite often affected by the incursion of Siberian and Saharan - and occasionally Arctic - air masses, resulting in severe cold and heat waves. Mean annual minimum and maximum temperatures in the Balearic Islands are $12.8^{\circ}$ and $21.8^{\circ} \mathrm{C}$, respectively (Homar et al. 2010).

The SPdP is located in the southwestern coast of Mallorca, neighboring the city of Palma (Fig. 1). It is the main tourist region in the Balearics and is situated within the municipalities of Palma and Llucmajor. The average of nights per year spent by visitors in the entire Palma county was more than 8 million during the 1999-2008 period (taking into account hotels and tourist apartments; INE 2010). In particular, the SPdP can host 40000 visitors per night with a total amount of 1.2 million nights spent per year. Its main socioeconomic activities rely on beachbased tourism, although it is also an important residential area-34 000 permanent inhabitants-owing to be a dormitory town of the main city of the Balearics (Fig. 1). It has $10-\mathrm{km}$ coastline, mainly consisting of sand beaches, and the dominant holiday activities are those related to the sun, sea, and sand tourism mass model.

\section{Database and methods}

\section{a. Input data and quantile-quantile adjustment}

Observations were obtained from the automatic weather station deployed in 1973 by the Spanish Meteorological Agency [Agencia Estatal de Meteorología (AEMET)] at Palma's international airport (denoted as LEPA; $39.37^{\circ} \mathrm{N}, 2.43^{\circ} \mathrm{E}$ ). No significant construction has been undertaken near this station, located at the head of the first runaway, far from any urban development (Fig. 1). Therefore, local effects from urbanization, such as heat island warming or precipitation sheltering, are safely negligible (Gual et al. 2002). Besides, its proximity to the SPdP-less than $4 \mathrm{~km}$-makes it an ideal dataset to address the objectives of this work. To characterize the evolution of the meteorological variables over the SPdP,
TABLE 1. List of transient RCM experiments driven within the ENSEMBLES European project for the 1951-2100 period. Note that all the models have a spatial resolution of $25 \mathrm{~km}$ and have been run under the SRES A1B.

\begin{tabular}{llll}
\hline \hline Driving GCM & \multicolumn{1}{c}{ RCM } & \multicolumn{1}{c}{ Acronym } & Institute \\
\hline ECHAM5 & RCA3 & C4IRCA3 & C4I \\
ARPEGE & HIRLAM & DMI-HIRLAM5 & DMI \\
ECHAM5 & HIRLAM & DMI-HIRLAM5 & DMI \\
BCM & HIRLAM & DMI-HIRLAM5 & DMI \\
HadCM3 & CLM & ETHZ-CLM & ETHZ \\
ECHAM5 & RegCM & ICTP-REGCM & ICTP \\
ECHAM5 & RACMO & KNMI-RACMO & KNMI \\
HadCM3 & HadRM3Q0 & METO-HC-HadCM3Q0 & HC \\
HadCM3 & HadRM3Q3 & METO-HC-HadCM3Q3 & HC \\
HadCM3 & HadRM3Q16 & METO-HC-HadCM3Q16 & HC \\
BCM & RCA & SMIRCA & SMHI \\
ECHAM5 & RCA & SMIRCA & SMHI \\
HadCM3 & RCA & SMIRCA & SMHI \\
\hline
\end{tabular}

complete daily series of 2-m minimum and maximum temperatures, accumulated precipitation, 2-m mean relative humidity, mean cloud cover, and 10-m mean wind speed for the entire 1973-2008 period (36 yr) have been used.

Regarding the future projections, we use the regional simulations database available from the ENSEMBLEbased predictions of climate changes and their impacts (ENSEMBLES) European project (Table 1; Hewitt 2004; further information at http://ensembles-eu.metoffice.com). These models were nested within four different driving general circulation models and were run from 1951 to 2100 under the SRES A1B scenario. The experiments were performed using a $25-\mathrm{km}$ horizontal grid-length resolution that spans Europe and includes the eastern part of the Atlantic, northern Africa, and western Asia. Daily-averaged simulated variables for each model have been bilinearly interpolated to LEPA from the four nearest grid points (Akima 1978, 1996).

Even if dynamical downscaling improves the representation of regional features in climate projections, some important local inaccuracies still remain owing to insufficient resolution and the uncertainties in the representation of small-scale forcings and processes (e.g., clouds, convection, boundary layer, radiative transfer). Several procedures exist to adjust RCM projections, taking local forcings into consideration. Two straightforward corrections consist of (i) adding the climatological difference between future and control climate scenario simulations to an observed baseline (the so-called delta method) and (ii) removing the bias from future simulation by applying the climatological difference between the observed and control data (the unbiasing method; Déqué 2007). These techniques assume that the variability in the climate scenario remains unchanged in the first case and that the RCM variability is perfect in the 
second case, two important assumptions. The application of the quantile-quantile mapping transformation is more flexible than the previous methods and is a procedure that has been widely used for correcting biases in the simulated meteorological variables (Wood et al. 2004; Reichle and Koster 2004; Déqué 2007; Boé et al. 2007). Within this context, we present a new quantile-quantile calibration method based on a nonparametric function that amends mean, variability, and shape errors in the simulated cumulative distribution functions (CDFs) of the climatic variables.

The procedure consists of calculating the changes, quantile by quantile, in the CDFs of daily RCM outputs between a 15-yr control period and successive 15-yr future time slices. These changes are rescaled on the basis of the observed CDF for the same control period, and then added, quantile by quantile, to these observations to obtain new calibrated future CDFs that convey the climate change signal. We have chosen periods of $15 \mathrm{yr}$ owing, first of all, to the temporal limitation of the observed database (36 yr): we have split the daily series into an early control period for the calibration task (1973-87; baseline) and a later interval for validation purposes (1994-2008); the remaining years (i.e., 198893) are used to perform a robustness test of the method (section $3 b$ ). Second, we consider a length of $15 \mathrm{yr}$ to be a compromise between series large enough to have climatological meaning-the statistical sample is $N=5478$ and short enough to permit, by comparing the simulated CDFs of successive 15-yr intervals starting in 2010, an effective isolation of any climate change signal along the twenty-first century.

Recalling that our control period extends from 1973 to 1987 and that the future periods comprise all subsequent 15-yr intervals after 2010, the statistical adjustment (developed in detail in the appendix) can be written as the following relationship between the $i$ th ranked value $p_{i}$ (projected or future calibrated), $o_{i}$ (control observed or baseline), $s_{\mathrm{ci}}$ (raw control simulated), and $s_{\mathrm{fi}}$ (raw future simulated) of the corresponding CDFs (Fig. 2):

$$
p_{i}=o_{i}+g \bar{\Delta}+f \Delta_{i}^{\prime},
$$

where

$$
\begin{aligned}
& \Delta_{i}=s_{\mathrm{fi}}-s_{\mathrm{ci}}, \\
& \bar{\Delta}=\frac{\sum_{i=1}^{N} \Delta_{i}}{N}=\frac{\sum_{i=1}^{N}\left(s_{\mathrm{fi}}-s_{\mathrm{ci}}\right)}{N}=\overline{S_{f}}-\overline{S_{c}}, \text { and } \\
& \Delta_{i}^{\prime}=\Delta_{i}-\bar{\Delta},
\end{aligned}
$$

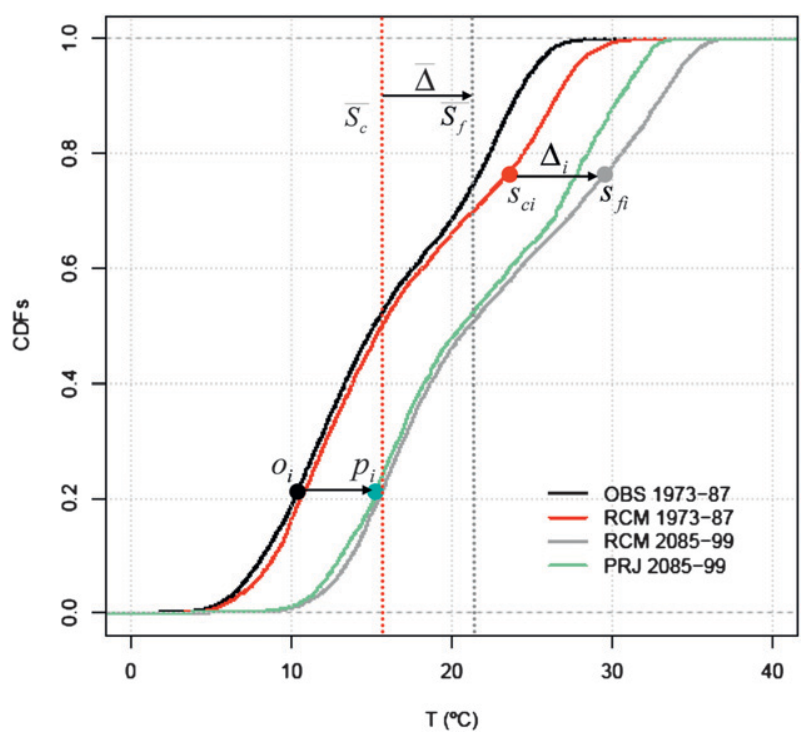

FIG. 2. Graphical sketch of the Q-Q adjustment. The CDFs of the mean temperatures are shown for the observed control (OBS 1973-87), raw control (RCM 1973-87), and future (RCM 2085-99) simulated, and calibrated or projected (PRJ 2085-99) data. The statistical correction is illustrated between the 15-yr past (1973-87) and future (2085-99) periods. Vertical lines denote mean values for raw control $\left(\overline{S_{c}}\right)$ and future $\left(\overline{S_{f}}\right)$ simulated periods.

and

$$
\begin{aligned}
& g=\frac{\left(\sum_{i=1}^{N} o_{i}\right) / N}{\left(\sum_{i=1}^{N} s_{\mathrm{ci}}\right) / N}=\frac{\bar{O}}{\overline{S_{c}}} \text { and } \\
& f=\frac{\sigma_{O}}{\sigma_{S_{c}}}=\frac{\left.\mathrm{IQR}\right|_{O}}{\left.\mathrm{IQR}\right|_{S_{c}}} .
\end{aligned}
$$

As surrogates of the population variability, $\left.\mathrm{IQR}\right|_{O}$ and $\left.\mathrm{IQR}\right|_{S_{c}}$ in (6) are the interquartile ranges of the observed and raw control simulated data, respectively - that is, the parametric difference between the 75th (P75) and 25th (P25) percentiles for all the considered variables, except for the precipitation for which we used the 90th (P90) and 10th (P10) percentiles owing to the highly asymmetrical gamma-type distribution of this variable, with a high proportion of nonrainy days. In the equations, $\Delta_{i}$ is the difference between the future and control raw $i$ th quantiles (Fig. 2). Therefore, it can be expressed as the sum of the mean regime shift $(\bar{\Delta})$ plus the corresponding deviation $\Delta_{i}^{\prime}$ from this shift [Eqs. (2)-(4)].

In Eq. (1), omission of $g$ and $f$ parameters (i.e., $g=f=1$ ) would be the special case in which $\Delta_{i}$ is simply added to 
the local control baseline without any further adjustment. Therefore, $g$ is a factor that modulates the variation in the mean state $\bar{\Delta}$, while $f$ calibrates the change in variability and shape expressed by $\Delta_{i}^{\prime}$. The use of $g$ and $f$ parameters serves to reconcile the RCM with the observed climate: a parameter value greater (smaller) than 1 would act to inflate (deflate) an otherwise too low (high) contribution to the change of the corresponding climate attribute (i.e., mean regime or spread). While the $f$ parameter is used for all variables (minimum and maximum temperatures, precipitation, relative humidity, cloudiness, and wind speed), for temperatures the $g$ parameter is not applied (i.e., $g=1$ ). This means that changes in the modeled temperature mean states are counted in absolute terms $(\bar{\Delta})$, whereas for the remaining variables, relative changes $(g \bar{\Delta})$ are employed instead, as widely applied in climate literature (see the appendix).

A difficulty arises for precipitation since RCMs tend to overestimate the number of days resulting in trace values but also to underestimate the number of nonrainy days, thus resulting in an unrealistic probability of precipitation in the simulations. To overcome this problem while respecting the internal dynamical evolution of the modeled climate scenario when dealing with the drying or moistening of the rainfall regimes, we impose an additional constraint: the ratio of nonrainy days between future and control simulated raw data is maintained for the calibrated versus observed series, which is

$$
n z_{p}=\frac{n z_{s_{f}}}{n z_{s_{c}}} n z_{o},
$$

where $n z_{p}, n z_{o}, n z_{s}$, and $n z_{s_{f}}$ are the number of zeros in the projected, observed, simulated control, and simulated future series, respectively.

\section{b. Validation of the quantile-quantile adjustment}

The use of a multimodel strategy - that is, a collection of different GCMs-attempts to encompass the uncertainties arising from model errors and boundary conditions provided by different GCMs (Table 1). We have first evaluated the performance of the multimodel mean by comparing the raw and calibrated data percentiles against the observed ones. Figure 3 shows their cumulative distribution functions for the 15-yr validation period (19942008). Table 2 displays the results of the quantile-wise mean absolute error (MAE) and root-mean-square error (RMSE) to evaluate the raw and calibrated CDFs. MAE and RMSE scores reveal an overall improvement of the calibrated versus uncalibrated CDFs for all the atmospheric parameters, with the exception of the RMSE for the precipitation. It is worth noting that large discrepancies obtained for extreme rainfall events and outliers that are due to the long-tailed distribution of this variable are especially penalized with the RMSE.

We also carry out a test to assess the sensitivity of the quantile-quantile correction to small variations in the training data. To this end, a bootstrap approximation is used by varying the control period of the statistical adjustment. We consider 1000 different 15 -yr control intervals by randomly selecting-without repetition-groups of those years included within the 1973-93 interval (21 yr). The $95 \%$ confidence interval is obtained as the 2.5 and 97.5 percentiles of the 1000 repetitions. The improvements observed in the MAE and RMSE for the referenced calibrated series are all robust to changes in the training set at the 5\% significance level. Again, precipitation shows a degradation attributable to undersampled extreme events.

Figures $3 \mathrm{a}$ and $3 \mathrm{~b}$ provide evidence that the application of the quantile-quantile correction results in a cooling and warming of the raw minimum and maximum temperatures, respectively. For the rainfall amounts, the method corrects the overestimation of the multimodel mean for trace values and the underestimation for medium and high rainfall thresholds (Fig. 3c). The relative humidity is also corrected by the approach, accounting for the fact that the multimodel mean shows an overall underestimation for this atmospheric parameter over the SPdP (Fig. 3d). Regarding cloud cover, the calibration only partially alleviates the overestimation in the number of almost-clear days simulated by the models, although it significantly amends the overestimation in the number of overcast days as well (Fig. 3e). Figure $3 \mathrm{f}$ shows that the uncalibrated multimodel mean results in wind regimes stronger than observed. Although these inaccuracies are amended for moderate and large wind speeds, the quantile-quantile technique still yields an underestimation of the small values. After all, the net result of applying the calibration is clearly beneficial (Table 2). Note that the uncertainty range due to intermodel differences is also reduced by the adjustment.

Q-Q plots emphasize the benefits of the statistical correction as well (Fig. 4). As expected, temperatures follow the most linear behavior and the calibrated data are barely diverted from the diagonal. To a lesser extent, this behavior is also found for the relative humidity and wind speed regimes. For precipitation, the quantile-quantile adjustment depicts improvements for most events up to $50 \mathrm{~mm}$ but produces an oversampling of calibrated extreme values as well. Regarding cloud cover, the method still yields an overestimation for small cloud fractions: it seems that RCMs strongly overrate the number of days with low cloud cover (Fig. 4e). Moreover, Figs. $4 \mathrm{c}$ and $4 \mathrm{f}$ also show the problems found when dealing with the precipitation and wind speed extremes. As mentioned earlier, 

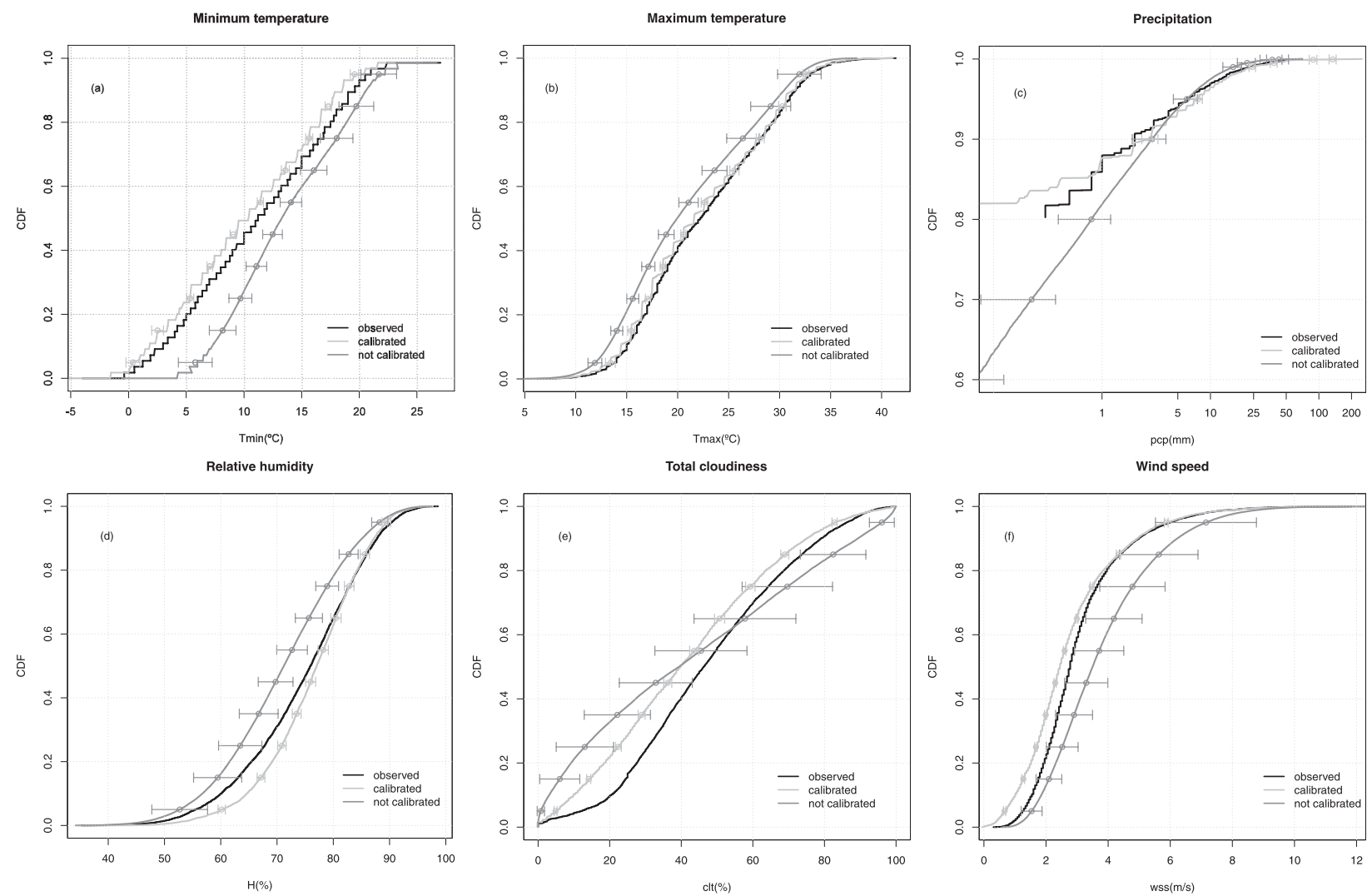

FIG. 3. Observed, raw, and calibrated multimodel mean CDFs for all the meteorological variables and the 1994-2008 validation period. It is worth noting that observed and calibrated minimum and maximum temperatures appear staggered owing to the effect of the numerical truncation to the nearby integer for the first years of measurements. Multimodel means and their standard deviation are shown.

the temporal limitation of our observed database could entail that the underlying distributions of both parameters might not be well sampled over 15 -yr periods, thus creating uncertainties in the tails when applying the quantile-quantile correction. These biases would be partially reduced by using longer observed daily series.

\section{c. Additional tests and comments}

Since biases in RCMs' distributions of daily variables could depend on the season, it is unclear whether the quantile-quantile adjustment ought to be applied annually or seasonally for the SPdP. Furthermore, we are interested in studying not only the annual changes in mean and extreme regimes but also their seasonal shifts, which may be sensitive to the application of such seasonal correction for our study area. To clarify these issues, an intercomparison between annual and seasonal calibrations has been carried out for our observed control baseline (i.e., 1973-87). Thus, the quantile-quantile adjustment has also been performed by using daily observed and simulated data for each season independently. For the sake of simplicity, we have defined seasons as winter ranging from December to February (DJF), spring spanning March-May (MAM), summer

TABLE 2. MAE and RMSE statistical indices for the 1994-2008 raw and calibrated multimodel mean CDFs for the indicated atmospheric parameters. Also shown between brackets are the $5 \%$ significance intervals for the calibrated CDFs.

\begin{tabular}{lccrr}
\hline \multicolumn{1}{c}{ Variable } & MAE raw & MAE calibrated & RMSE raw & RMSE calibrated \\
\hline Min temperature $\left({ }^{\circ} \mathrm{C}\right)$ & 2.59 & $0.98[0.74,1.02]$ & 2.86 & 1.87 \\
Max temperature $\left({ }^{\circ} \mathrm{C}\right)$ & 1.84 & $0.39[0.25,0.48]$ & 1.20 & $0.45[0.77,1.07]$ \\
Precipitation $(\mathrm{mm})$ & 0.34 & $0.29[0.22,0.33]$ & $3.54]$ \\
Relative humidity $(\%)$ & 3.84 & $1.79[1.64,3.36]$ & 3.94 & $2.58,4.42]$ \\
Cloudiness $(\%)$ & 9.86 & $6.29[5.37,6.49]$ & 11.41 & $2.37[2.30,3.84]$ \\
Wind speed $\left(\mathrm{m} \mathrm{s}^{-1}\right)$ & 0.75 & $0.30[0.25,0.36]$ & 0.83 & $6.72[5.96,6.99]$ \\
\hline
\end{tabular}



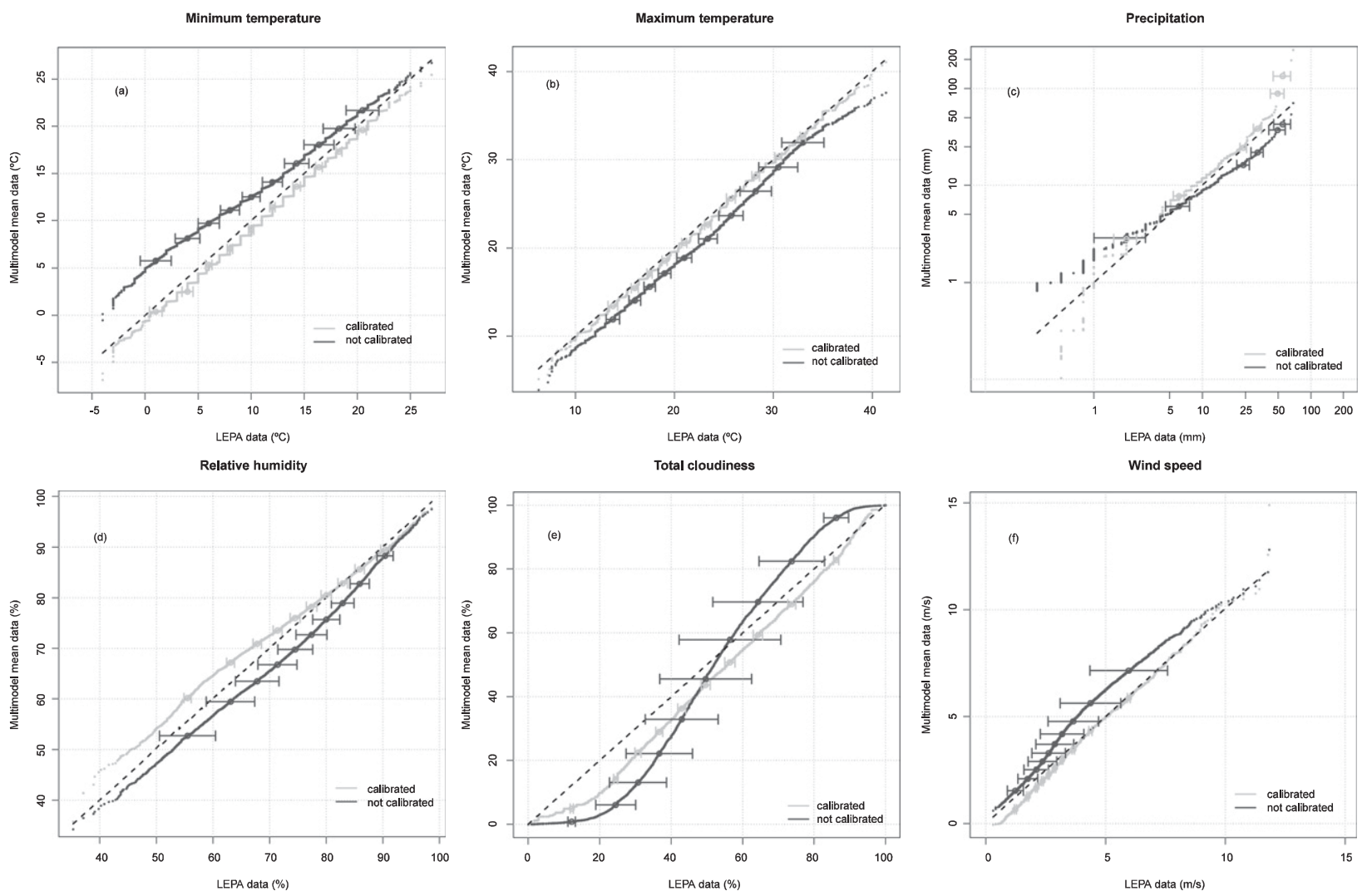

FIG. 4. Raw and calibrated multimodel mean Q-Q plots for all the meteorological variables. It is worth noting that observed and calibrated minimum and maximum temperatures appear staggered owing to the effect of the numerical truncation to the nearby integer for the first years of measurements. Multimodel means and their standard deviation are shown.

covering June-August (JJA), and autumn extending from September to November (SON). The results do not depict any relevant improvement by conducting the adjustment for each season separately over the SPdP: the benefits of considering a seasonal instead of an annual calibration depends on the variable and the season (Table 3). In addition, the aforementioned sampling limitation in our observed database would be accentuated by introducing seasonal-dependent correction functions. However, these conclusions cannot be extrapolated to other locations and climates, and it would be generally desirable to test a seasonal-dependent quantile-quantile adjustment and its possible benefits.

We have also carried out an intercomparison between the quantile-quantile adjustment presented in this work and the scheme used by Wood et al. (2004) and Boé et al. (2007; denoted herein as the SPdP and WB methods, respectively). To illustrate the differences between both corrections, we use the Weibull distribution to generate a set of theoretical probability distribution functions (PDFs) and associated CDFs for the daily atmospheric parameters. Figure 5a shows the performance of both methods when only small changes in means are found among the observed, control, and future simulated theoretical distributions. For this case, both corrections adjust identically the projected climate. When small differences among distributions are not only attributable to shifts in the mean state but also to variability and distribution shape, both adjustments yield very similar projected distribution functions (Fig. 5b). However, when these changes are either not so small or the distributions are not so well behaved, the SPdP and WB methods clearly differ (cf. CDFs and PDFs in Fig. 5c).

To further assess the differences between the SPdP and WB corrections when changes in the CDFs are expected to be more remarkable, we perform an additional test. The best model among available RCMs, in terms of simulating the daily atmospheric variables for our 15 -yr observed control baseline, has been selected [Regional Climate Model (RegCM) in Table 1]. Then, we have considered raw RegCM data from the control baseline (i.e., 1973-87) and a future 15-yr period (2084-98) as the "observations" for calibration and validation purposes. That is, the remaining RCMs have been calibrated by applying the SPdP and WB adjustments on the basis of these raw model data for the control and future periods. Then, raw and 
TABLE 3. MAE and RMSE statistical indices for the 1994-2008 calibrated multimodel mean CDFs for the indicated atmospheric parameters. The adjustments have been conducted by using daily annual data, later divided into seasons, and by using daily seasonal data. Best scores are highlighted in bold.

\begin{tabular}{|c|c|c|c|c|}
\hline Variable & $\begin{array}{c}\text { MAE } \\
\text { annual }\end{array}$ & $\begin{array}{c}\text { MAE } \\
\text { seasonal }\end{array}$ & $\begin{array}{l}\text { RMSE } \\
\text { annual }\end{array}$ & $\begin{array}{c}\text { RMSE } \\
\text { seasonal }\end{array}$ \\
\hline \multicolumn{5}{|l|}{ Winter } \\
\hline Min temperature $\left({ }^{\circ} \mathrm{C}\right)$ & 0.87 & 0.53 & 0.90 & 0.60 \\
\hline Max temperature $\left({ }^{\circ} \mathrm{C}\right)$ & 0.29 & 0.33 & 0.35 & 0.45 \\
\hline Precipitation $(\mathrm{mm})$ & 0.30 & 0.40 & 1.73 & 3.14 \\
\hline Relative humidity (\%) & 1.33 & 0.67 & 1.59 & 0.92 \\
\hline Cloudiness $(\%)$ & 6.61 & 5.71 & 6.96 & 6.20 \\
\hline Wind speed $\left(\mathrm{m} \mathrm{s}^{-1}\right)$ & 0.57 & 0.37 & 0.60 & 0.42 \\
\hline \multicolumn{5}{|l|}{ Spring } \\
\hline Min temperature $\left({ }^{\circ} \mathrm{C}\right)$ & 1.61 & 1.41 & 1.68 & 1.43 \\
\hline Max temperature $\left({ }^{\circ} \mathrm{C}\right)$ & 1.00 & 1.27 & 1.03 & 1.29 \\
\hline Precipitation $(\mathrm{mm})$ & 0.54 & 0.56 & 2.55 & 2.23 \\
\hline Relative humidity (\%) & 3.14 & 2.86 & 4.08 & 3.51 \\
\hline Cloudiness $(\%)$ & 7.78 & 3.04 & 8.05 & 3.31 \\
\hline Wind speed $\left(\mathrm{m} \mathrm{s}^{-1}\right)$ & 0.34 & 0.38 & 0.40 & 0.40 \\
\hline \multicolumn{5}{|l|}{ Summer } \\
\hline Min temperature $\left({ }^{\circ} \mathrm{C}\right)$ & 1.20 & 1.31 & 1.23 & 1.36 \\
\hline Max temperature $\left({ }^{\circ} \mathrm{C}\right)$ & 0.44 & 0.56 & 0.48 & 0.63 \\
\hline Precipitation $(\mathrm{mm})$ & 0.10 & 0.35 & 1.52 & 5.53 \\
\hline Relative humidity (\%) & 2.67 & 1.74 & 3.05 & 2.05 \\
\hline Cloudiness $(\%)$ & 4.77 & 6.80 & 5.27 & 7.21 \\
\hline Wind speed $\left(\mathrm{m} \mathrm{s}^{-1}\right)$ & 1.07 & 0.39 & 1.10 & 0.43 \\
\hline \multicolumn{5}{|l|}{ Autumn } \\
\hline Min temperature $\left({ }^{\circ} \mathrm{C}\right)$ & 0.27 & 0.79 & 0.45 & 0.97 \\
\hline Max temperature $\left({ }^{\circ} \mathrm{C}\right)$ & 0.39 & 0.52 & 0.49 & 0.67 \\
\hline Precipitation $(\mathrm{mm})$ & 0.46 & 0.51 & 5.53 & 4.22 \\
\hline Relative humidity (\%) & 1.13 & 1.50 & 1.51 & 1.75 \\
\hline Cloudiness $(\%)$ & 6.21 & 9.88 & 7.33 & 10.36 \\
\hline Wind speed $\left(\mathrm{m} \mathrm{s}^{-1}\right)$ & 0.28 & 0.46 & 0.36 & 0.47 \\
\hline
\end{tabular}

calibrated multimodel mean data have been validated against the "observed" future. Table 4 depicts the results of the quantile-wise MAE and RMSE for the future validation period. The SPdP correction appears to be more accurate for most variables, although no significant improvements are found for precipitation and relative humidity when comparing both quantile-quantile adjustments.

A sensitivity test of the SPdP method to the $g$ and $f$ parameters has also been conducted. To this aim, an additional experiment has been performed either considering or not (i.e., $g=f=1$ ) both factors when calibrating the theoretical distributions. Recall that $g$ is the term that regulates the variation in the mean state, while $f$ accounts for the change in the variability and shape among the observed and simulated CDFs. Figure 5d depicts the impact of including these parameters. The use of $g$ and $f$ clearly prevents the contamination of the projection with the excessive error found in the mean state and spread of the simulated control data in comparison with the observed baseline.
Finally, the quantile-quantile adjustment applied on bounded variables could produce anomalous behavior in certain situations. Specifically, projected quantiles should always remain nonnegative, but admittedly this requirement cannot be generally guarantied from Eq. (1). For example, negative winds or negative rainfalls have no physical sense and must be avoided. Similarly, projected quantiles of relative humidity and cloudiness should not exceed their upper bounds. We have checked these possible anomalies of the adjustment. Out of the total sample of 426933 projected daily values for each physical variable (considering the whole set of RCMs and the full 2010-99 period), no negative values were found for precipitation. For wind, only $0.19 \%$ of the data was negative, but with the largest negative value not exceeding -0.1 $\mathrm{m} \mathrm{s}^{-1}$. With regard to relative humidity, neither negative values nor values greater than $100 \%$ were detected. For cloudiness, $1.58 \%$ of the sample was negative, never below $-1 \%$ of cloud cover, and only $0.01 \%$ of the values became greater than $100 \%$, by less than two-tenths. When these infrequent pathologies occur in the method, we simply round unphysical values to the corresponding lower or upper bound.

\section{Results and discussion}

\section{a. Changes in annual regimes}

Once RCM outputs have been adjusted statistically to the SPdP, we analyze the climate change signal by studying the changes obtained from the 1973-2002 observed time slice (present) and the multimodel means of three future 30-yr time slices: 2010-39 (early twenty-first century), 2040-69 (mid-twenty-first century) and 2070-99 (late twenty-first century). It is worth noting that the $30-y r$ future periods have been obtained as simple aggregations of successive 15 -yr future calibrated data periods. Table 5 displays the changes in the climatic annual mean regimes for the parameters of interest together with their associated uncertainties. An overall increment of the minimum and maximum temperatures in the SPdP can be expected during the twenty-first century. Solomon et al. (2007) points out, under the A1B scenario, an annual mean warming between the 1980 and 1999 and 2080 and 2099 periods varying from $2.2^{\circ}$ to $5.1^{\circ} \mathrm{C}$ in the southern Europe and Mediterranean (SEM) region. We have obtained for the latter twenty-first century, annual mean regime shifts for minimum and maximum temperatures roughly of $2.7^{\circ}$ and $3.0^{\circ} \mathrm{C}$, respectively. Therefore, the projections for the SPdP indicate a rise in temperatures slightly above the lower limit of the expected change for the SEM area. This fact can be due to the dominant maritime characteristics of the SPdP insular environment. Note that the growth of the 
(a)
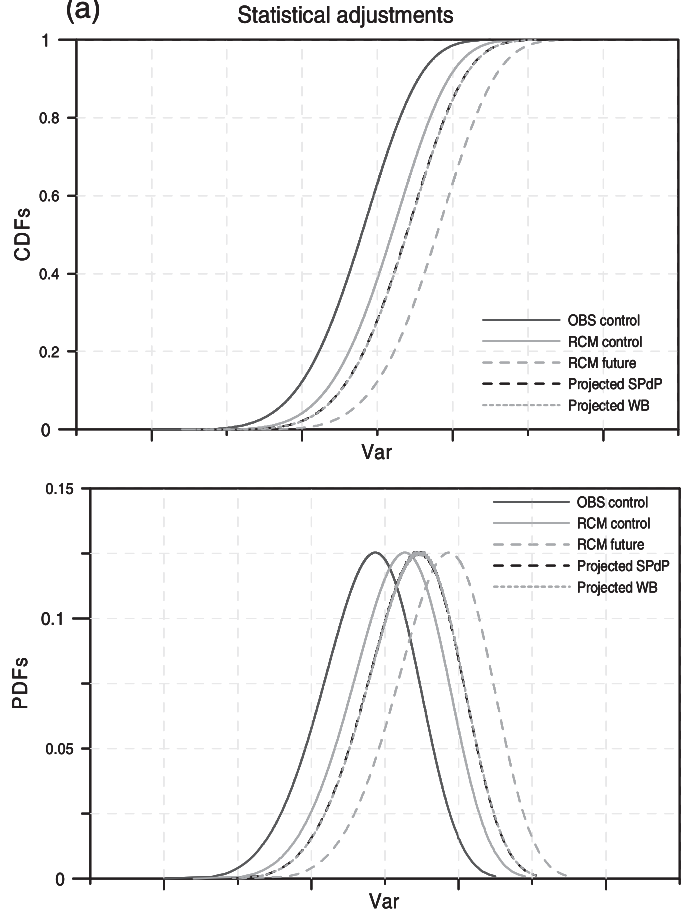

(c)
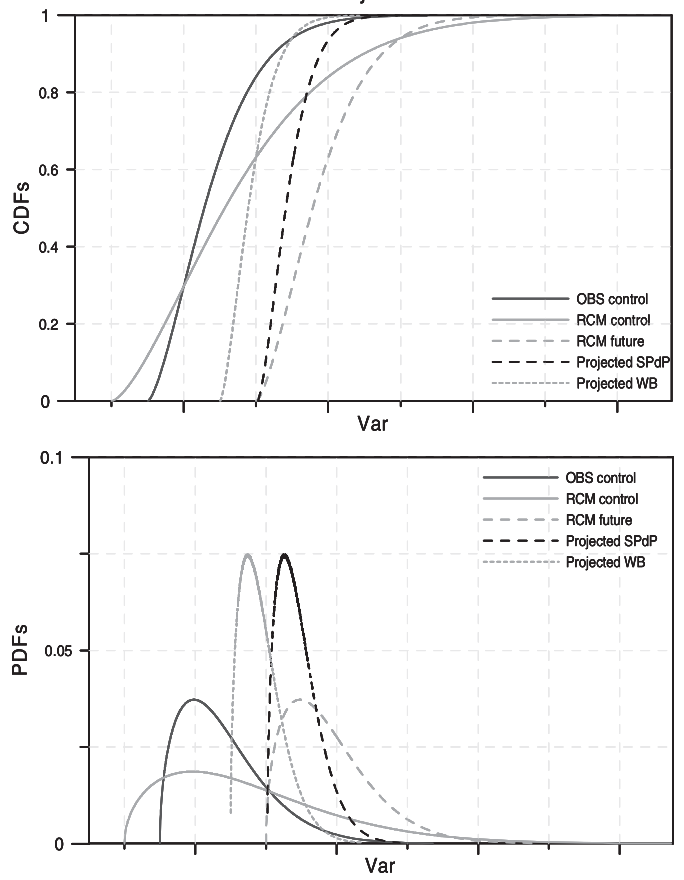

(b)
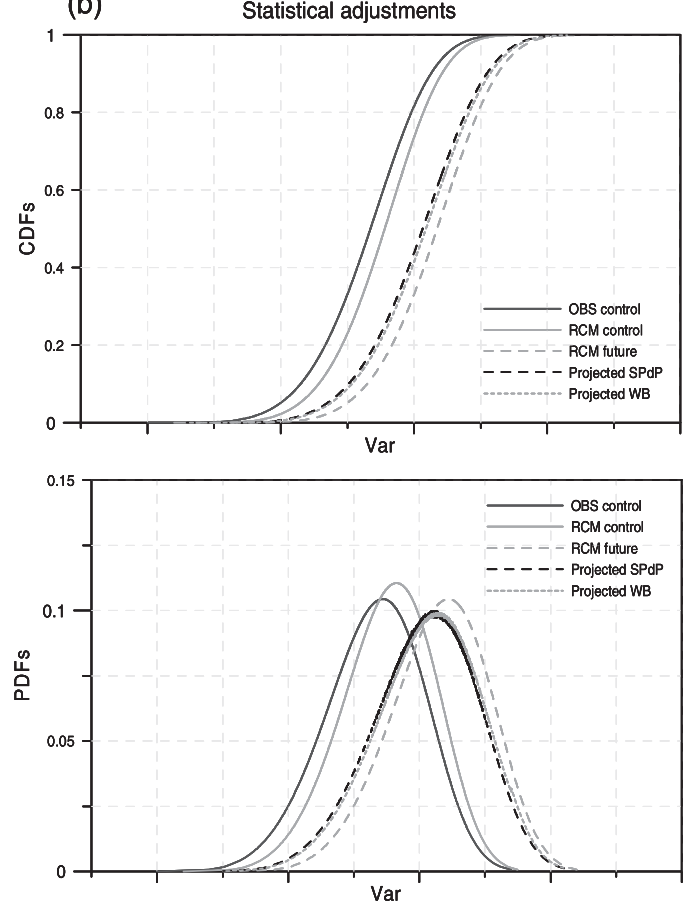

(d)
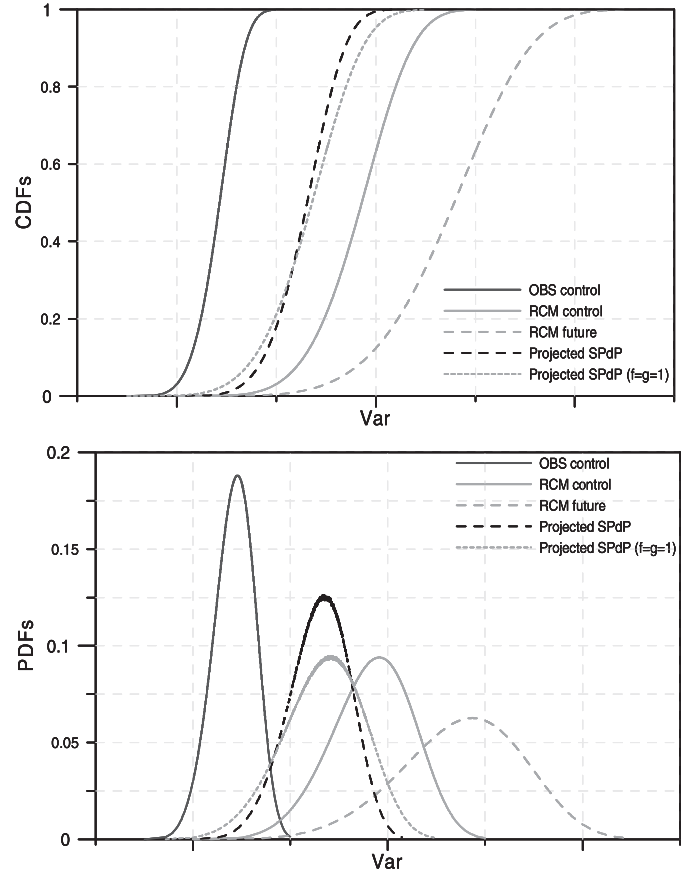

Var

FIG. 5. Performance of the SPdP and WB corrections for (a) changes only in mean and (b),(c) changes in mean, variability, and shape of the PDFs and CDFs. (d) Performance of the SPdP technique by considering or not the $f$ and $g$ parameters.

mean maximum temperatures is projected to be faster than for the daily minima, which would denote a further expansion of the diurnal temperature range (DTR) in the SPdP.
Projections obtained from several AOGCMs point out a decrease in precipitation ranging from $-4 \%$ to $-27 \%$ in the SEM region for the same period (Solomon et al. 2007). For the SPdP, annual rainfall amounts are projected to rise 
TABLE 4. MAE and RMSE statistical indices for the 2084-98 raw and calibrated multimodel mean CDFs for the indicated atmospheric parameters. Adjusted data have been obtained by applying the SPdP and WB Q-Q techniques.

\begin{tabular}{|c|c|c|c|c|c|c|}
\hline Variable & MAE raw & MAE SPdP & MAE WB & RMSE raw & RMSE SPdP & RMSE WB \\
\hline Min temperature $\left({ }^{\circ} \mathrm{C}\right)$ & 2.40 & 0.47 & 0.58 & 2.42 & 0.49 & 0.71 \\
\hline Max temperature $\left({ }^{\circ} \mathrm{C}\right)$ & 1.15 & 0.30 & 1.05 & 1.51 & 0.36 & 1.13 \\
\hline Annual precipitation $(\mathrm{mm})$ & 0.13 & 0.10 & 0.09 & 0.13 & 0.29 & 0.27 \\
\hline Relative humidity (\%) & 3.13 & 1.12 & 1.09 & 4.19 & 1.48 & 1.42 \\
\hline Cloudiness $(\%)$ & 11.48 & 3.26 & 3.68 & 12.96 & 3.69 & 4.13 \\
\hline Wind speed $\left(\mathrm{m} \mathrm{s}^{-1}\right)$ & 1.15 & 0.10 & 0.14 & 1.34 & 0.12 & 0.14 \\
\hline
\end{tabular}

into the early twenty-first century, and then fall by about $-7 \%$ by the end of the century (Fig. 6a). Again, the drop in the annual accumulation is found around the lower limit of the decrease projected by the IPCC for the SEM region. For the remaining parameters, a fall in their annual means can be anticipated. Even if a straightforward relationship between both variables is delusive, the drop in the mean cloud cover at a faster rate than the annual precipitation might reveal an extension of the past and present detected trend in the Mediterranean Basin: an increase of extreme daily rainfall despite the fact that total rainfall amounts decrease (Alpert et al. 2002). Furthermore, a reduction of windiness into the first decades with respect to the present climate is projected to maintain after a steady evolution in the course of the century (Table 5; Fig. 6a). For this parameter, the change in the large-scale atmospheric circulation, as the northward shift in cyclone activity over Europe found in many climate simulations, is a key factor (Räisänen et al. 2004; Leckebusch et al. 2006).

With regard to the extreme values, $5 \%$ and $95 \%$ (P05 and $\mathrm{P} 95$, respectively) observed percentiles are defined as the thresholds for which we define a low and high extreme event, except for the low rainfall extreme, which is more properly defined as a nonrainy event (Table 6). Note that we define high rainfall extremes as the 95th rainfall thresholds, well below the problematic outlier values, and so their degrading impact on the results is allegedly small. In the Mediterranean climate, daily temperatures present a characteristic bimodal distribution owing to four distinct seasons: cold winters, cool to mild springs, temperate autumns, and hot summers. Recall that the seasons have been defined as: DJF: winter,
MAM: spring, JJA: summer, and SON: autumn. We have calculated the climatic average annual number of projected days that are expected to fall outside the predefined thresholds to study the changes in their frequencies for each future time slice. As an example, Fig. 7 illustrates the temporal evolution of the distribution for the minimum temperature, revealing the shift of the histogram toward higher temperatures across the future time slices.

Regarding daily precipitations, a constant rise in the annual number of nonrainy days as well as a very slight growth in the frequency of extreme daily amounts can be expected (Figs. 6b and 6c). As mentioned, this fact appears to be consistent with the current observed trends for the Mediterranean Basin. These trends reveal an increase in the annual frequency of extreme rainfalls (i.e., an increasing frequency of weak and heavy precipitations). A notable and persistent fall in the annual number of very humid days is also detected, together with a slight growth in the number of days per year with relatively low humidity from midcentury. The multimodel mean also projects a rise in the annual number of clear days and a decrease in the number of overcast ones. Finally, the frequency of strong winds could slightly diminish in the future time slices, but a considerable growth in the frequency of weak wind regimes is also found (Figs. $6 \mathrm{~b}$ and $6 \mathrm{c}$ ).

\section{b. Changes in seasonal regimes}

With regard to the projected seasonal results, the change in mean regimes would indicate an overall rise of the minimum temperature for all seasons at the end of the century, being more marked for summers and autumns

TABLE 5. Multimodel annual mean regimes of the climatic variables for the present, early, middle, and late twenty-first-century time slices. Also shown between brackets is the standard deviation of the multimodel mean regimes.

\begin{tabular}{lcccc}
\hline \hline \multicolumn{1}{c}{ Annual } & Present & Early & Middle & Late \\
\hline Min temperature $\left({ }^{\circ} \mathrm{C}\right)$ & 10.1 & $10.6[10.2,11.0]$ & $11.7[11.1,12.3]$ & $12.8[11.9,13.7]$ \\
Max temperature $\left({ }^{\circ} \mathrm{C}\right)$ & 22.3 & $23.0[22.6,23.4]$ & $24.1[23.5,24.7]$ & $25.3[24.5,26.1]$ \\
Annual precipitation $(\mathrm{mm})$ & 463.3 & $496.0[474.9,517.1]$ & $457.8[419.2,496.4]$ & $431.5[404.1,458.2]$ \\
Relative humidity $(\%)$ & 77.1 & $75.9[75.2,76.6]$ & $74.9[73.5,76.3]$ & $74.2[72.7,75.7]$ \\
Cloudiness $(\%)$ & 43.7 & $40.6[40.0,41.2]$ & $39.4[38.3,40.5]$ & $38.5[37.3,39.7]$ \\
Wind speed $\left(\mathrm{m} \mathrm{s}^{-1}\right)$ & 2.9 & $2.7[2.7,2.7]$ & $2.7[2.7,2.7]$ & $2.7[2.7,2.7]$ \\
\hline
\end{tabular}


(a)

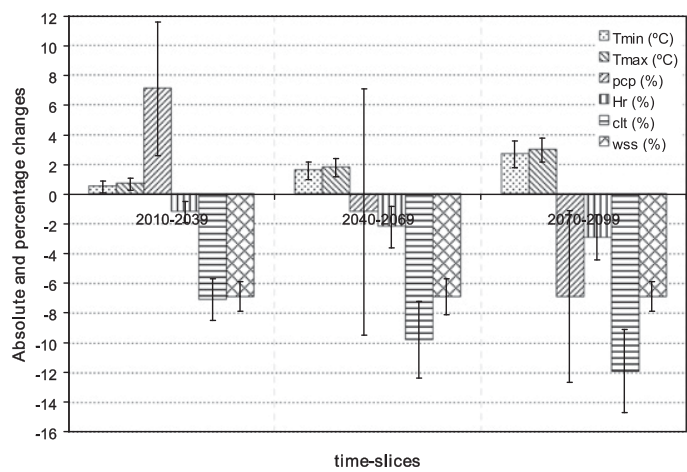

(c)

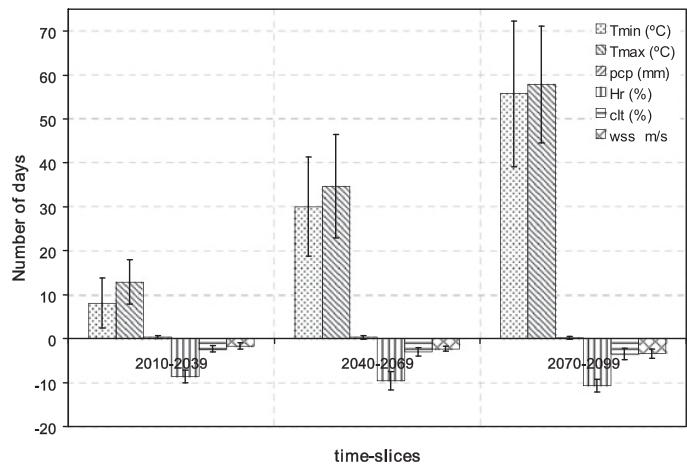

(b) Changes in annual low extreme regimes

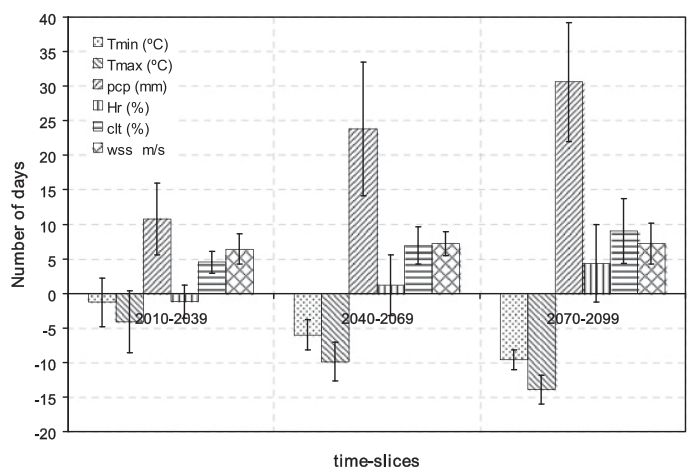

FIG. 6. (a) Annual mean and (b),(c) extreme regimes shifts of $T_{\min }$ and $T_{\max }$, precipitation (pcp), relative humidity $\left(H_{r}\right)$, cloud cover (clt), and wind speed (wss) for the early, middle, and late twenty-first-century time slices. It is worth noting that the changes in the number of days are computed as the difference among the projected and present extreme days. Multimodel means and their standard deviation are shown.

$\left(3.6^{\circ}\right.$ and $3.5^{\circ} \mathrm{C}$, respectively, for the late twenty-first century; Fig. 8a; Tables 7-10). The projections point out a general decrease in the frequency of the minimum temperature extremes as well (see Table 6 for a revision of the seasonal thresholds). Specifically, the extreme cold days (i.e., $T_{\min }$ in winter $<-1.0^{\circ} \mathrm{C}$ ) would be less frequent by almost 4 days per year at the end of the twenty-first century (Fig. 9a). The seasonal maximum temperatures show the highest growth rate in summer $\left(3.9^{\circ} \mathrm{C}\right.$ for the late twenty-first century) and, according to the results, a slight drop of the autumn mean is obtained for the early twentyfirst century, but without a very high statistical confidence in this shift. However, the general trend points toward a significant increase in the seasonal mean regimes along the century (Fig. 8b; Tables 7 to 10). The frequency of extreme warm days (i.e., $T_{\max }$ in summer $>35.0^{\circ} \mathrm{C}$ ) is expected to steadily increase, almost achieving the 30 days per year for the late time slice (Fig. 10b). Note also the change in the extreme regime expected for the last decades of the century in autumn, with an increase of more than 20 days per year with respect to the present. Therefore, the number of heat waves per year affecting the SPdP in summertime could increase, although the temporal persistence of such extreme warm days has not been examined explicitly. This fact could result in a worsening of the thermal discomfort situations for local residents and tourists.

TABLE 6. Annual and seasonal minimum and maximum extreme thresholds for all the atmospheric variables. These thresholds have been obtained from the 5th and 95th percentiles of the 1973-2002 time slice. The thresholds remain constant for the future time slices.

\begin{tabular}{|c|c|c|c|c|c|c|c|c|c|c|}
\hline \multirow[t]{2}{*}{ Variable } & \multicolumn{2}{|c|}{ Annual thresholds } & \multicolumn{2}{|c|}{ Winter thresholds } & \multicolumn{2}{|c|}{ Spring thresholds } & \multicolumn{2}{|c|}{ Summer thresholds } & \multicolumn{2}{|c|}{ Autumn thresholds } \\
\hline & 5 th & 95 th & 5 th & 95 th & 5 th & 95 th & 5 th & 95 th & 5 th & 95th \\
\hline Min temperature $\left({ }^{\circ} \mathrm{C}\right)$ & 0.0 & 19.8 & -1.0 & 11.0 & 0.8 & 14.0 & 12.0 & 21.6 & 3.7 & 19.0 \\
\hline Max temperature $\left({ }^{\circ} \mathrm{C}\right)$ & 13.2 & 32.6 & 11.0 & 19.6 & 14.0 & 26.8 & 24.0 & 35.0 & 15.8 & 30.0 \\
\hline Precipitation $(\mathrm{mm})$ & 0.0 & 24.9 & 0.0 & 19.1 & 0.0 & 18.9 & 0.0 & 35.1 & 0.0 & 30.5 \\
\hline Relative humidity (\%) & 59.5 & 91.2 & 64.6 & 93.4 & 58.7 & 90.4 & 55.5 & 84.9 & 64.0 & 90.7 \\
\hline Cloudiness (\%) & 5.7 & 85.0 & 12.5 & 88.1 & 10.0 & 88.7 & 1.2 & 70.0 & 11.9 & 83.1 \\
\hline Wind speed $\left(\mathrm{m} \mathrm{s}^{-1}\right)$ & 0.8 & 6.1 & 0.5 & 6.7 & 1.3 & 6.1 & 1.7 & 5.2 & 0.8 & 6.0 \\
\hline
\end{tabular}



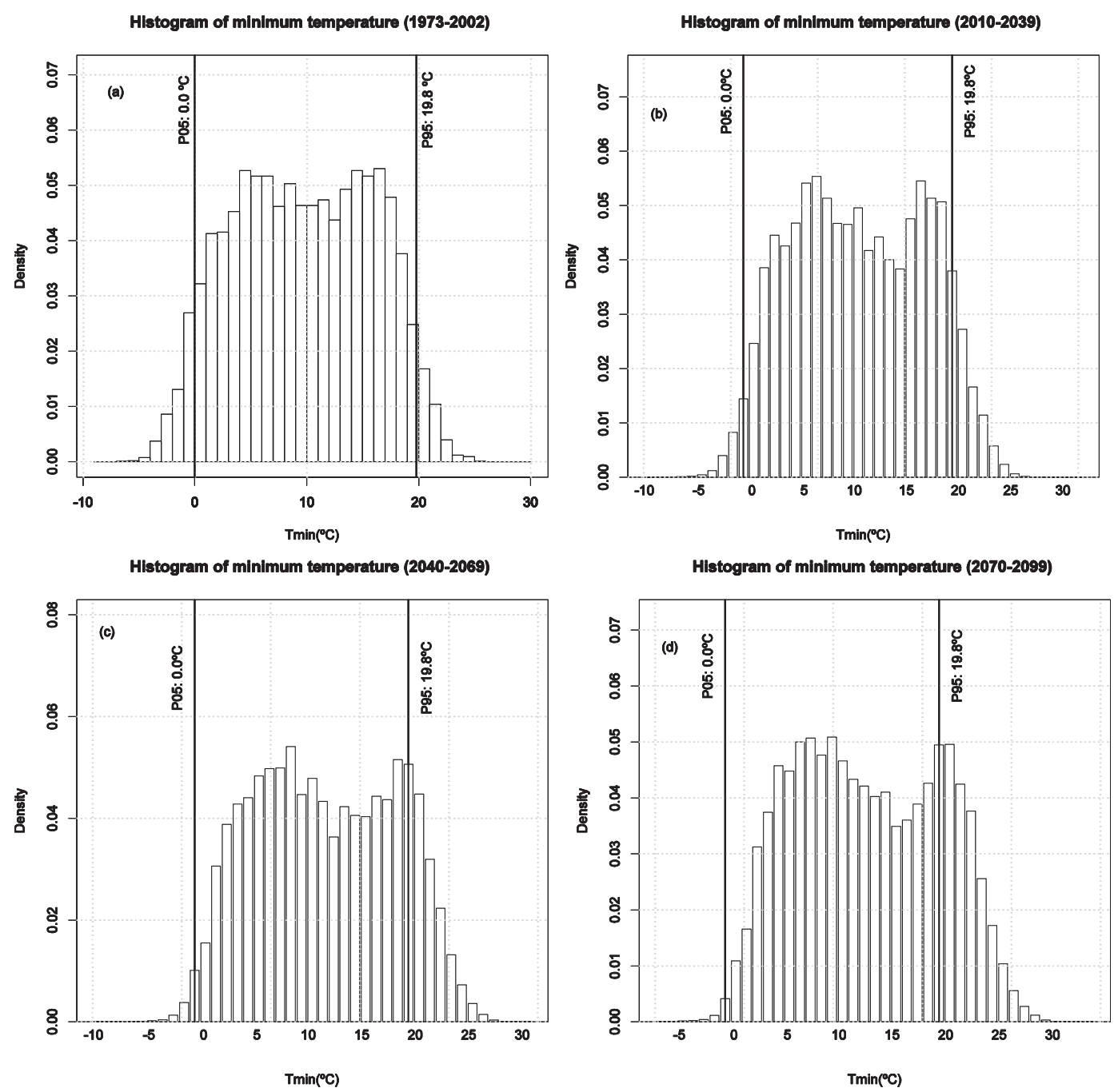

FIG. 7. Histograms of the observed and projected minimum temperatures. The P05 and P95 thresholds superimposed in the graphs have been defined from the observed distribution: (top) (left) 1973-2002 and (right) 20102030; (bottom) (left) 2040-2060 and (right) 2070-2099.

In the Balearics, the largest contribution to the inland natural water resources comes from the rainfall collected in autumn. The projected mean seasonal rainfall regimes indicate an increase in the autumn total amounts, most noticeably for the early twenty-first century $(+20.5 \%$; Table 10). The spring contribution is found to increase until the last third of the century. The winter portion to the water storage is expected to decrease for the first third but to increase slightly from the mid-2050s. In summertime, the typically scarce rainfall amounts are projected to fall throughout the century (up to $-51.5 \%$ at the end of the century; Table 9; Fig. 8c). However, percentage changes in precipitation amounts also present very high uncertainties for all seasons and periods. The cause of a substantial and widespread decrease in precipitation over the whole Mediterranean Basin for the late twenty-first century could be ascribed to summertime enhancement of the anticyclonic circulation over the northeastern Atlantic. This might indicate an increase of ridge patterns over western Europe and trough patterns over eastern Europe, resulting in a blocking structure that could deflect storms northward (Giorgi et al. 2004).

The expected changes in the mean seasonal regimes would require new efforts by local policy makers to adapt the present water management strategies to the new conditions. Furthermore, the projected seasonal number of days without precipitation is constantly increasing (Fig. 9c), in agreement with several previous studies (e.g., Semenov and Bengtsson 2002; Voss et al. 2002; Räisänen et al. 2004; Frei et al. 2006). The frequency of intense daily rainfall events is also projected to grow steadily for all seasons; however, for summers, this rise is 
(a) Absolute changes in seasonal mean regimes for minimum temperature

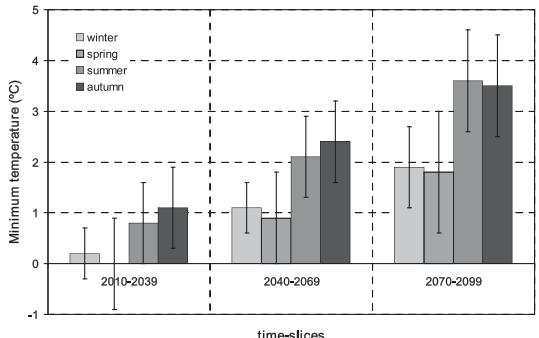

time-slices (d) Percentage changes in seasonal mean regimes for relative
humidity

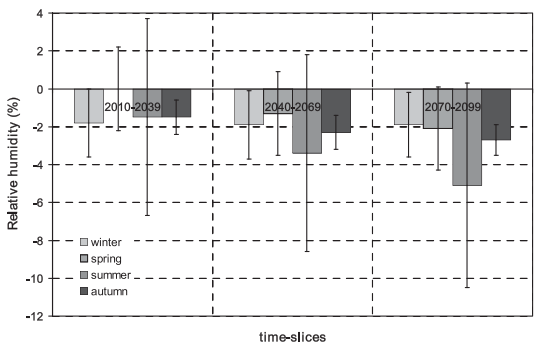

(b)

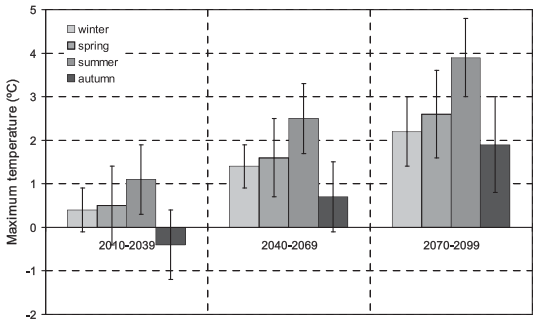

time-slices

(e) Percentage changes in seasonal mean regimes for cloudiness

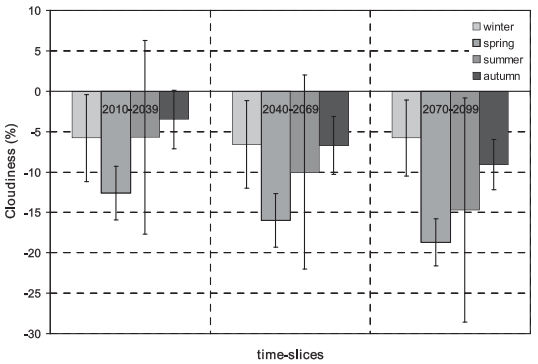

(C) Percentage changes in seasonal mean regimes for precipitation

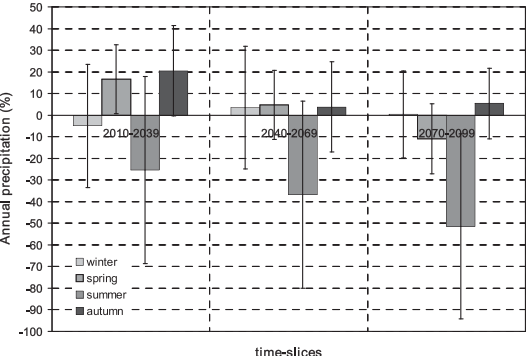

time-slices

(f) Percentage changes in seasonal mean regimes for wind speed

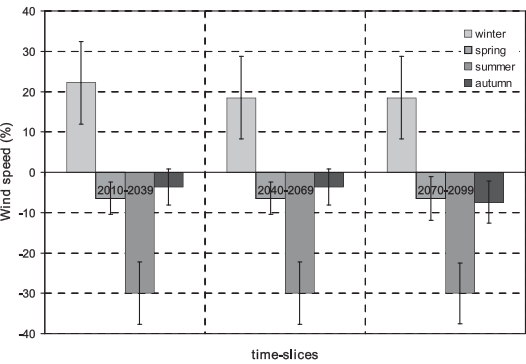

FIG. 8. Seasonal mean regimes changes with respect to present for the climate variables in the early, middle, and late twenty-first-century time slices. Multimodel means and their standard deviation are shown.

projected to be more noticeable for the first two-thirds of the century (Fig. 10c). Numerous works point out a substantial increase in the intensity of daily precipitation events for the late twenty-first century-even in regions where a decrease of precipitation is found-such as central Europe and the Mediterranean (Christensen and Christensen 2003; Giorgi et al. 2004; Kjellström 2004). However, the impact over the Mediterranean during summer is not clear because of the strong convective rainfall component and its high spatial variability (Llasat 2001).

For the relative humidity, a general decrease in the mean seasonal values is expected, resulting in a drying of the environment (Fig. 8d; Tables 7-10). Thus, the potential consequences of all these changes for the ecosystem and the environmental management of the area should be taken into consideration as well. The frequency of dry extremes continuously increases for summers and autumns (close to 4 days per year for the former season in the late twenty-first century), and a remarkable decrease in the maximum extremes is also found (Figs. 9d and 10d). Figure $8 \mathrm{e}$ depicts a steady decrease during the century for the cloud cover fraction for all seasons. This overall decrease in total cloudiness is consistent with the trends found for the mean and extreme regimes (Figs. $9 \mathrm{e}$ and $10 \mathrm{e})$.

Finally, mean wind speeds show uneven changes in the distributions depending on the season: a notable wind speed rise for winter, a moderate decrease during spring and autumn, and an important drop in summertime (Fig. 8f; Tables 7-10). For the minimum extremes, a general increase in the seasonal number of days below the corresponding thresholds would be expected, except for winters (Fig. 9f). Observe the important variation-an increase of more than 30 days-obtained for the lowest summer wind speed regimes: this change could be a consequence of a simulated increase in the number of days with anticyclonic circulation over the western Mediterranean. However, light to moderate (i.e., $\sim 5 \mathrm{~m} \mathrm{~s}^{-1}$ )

TABLE 7. Multimodel winter mean regimes of the climatic variables for the present, early, middle, and late twenty-first-century time slices. Also shown between brackets is the standard deviation of the multimodel mean regimes.

\begin{tabular}{lcccc}
\hline \hline \multicolumn{1}{c}{ Winter } & Present & Early & Middle & Late \\
\hline Min temperature $\left({ }^{\circ} \mathrm{C}\right)$ & 4.3 & $4.5[4.1,4.9]$ & $5.4[4.9,5.9]$ & $6.2[5.4,7.0]$ \\
Max temperature $\left({ }^{\circ} \mathrm{C}\right)$ & 15.7 & $16.1[15.7,16.5]$ & $17.1[16.6,17.6]$ & $17.9[17.1,18.7]$ \\
Precipitation $(\mathrm{mm})$ & 122.9 & $116.8[96.3,137.3]$ & $127.2[92.2,162.2]$ & $123.3[98.5,148.1]$ \\
Relative humidity $(\%)$ & 81.5 & $79.7[77.9,81.5]$ & $79.6[77.8,81.4]$ & $79.6[77.9,81.3]$ \\
Cloudiness $(\%)$ & 50.2 & $47.3[44.9,49.7]$ & $46.9[44.2,49.6]$ & $47.3[44.9,49.7]$ \\
Wind speed $\left(\mathrm{m} \mathrm{s}^{-1}\right)$ & 2.7 & $3.3[3.0,3.6]$ & $3.2[2.9,3.5]$ & $3.2[2.9,3.5]$ \\
\hline
\end{tabular}


TABLE 8. As in Table 7, but for the multimodel spring mean regimes of the climatic variables.

\begin{tabular}{lcccc}
\hline \multicolumn{1}{c}{ Spring } & Present & Early & Middle & Late \\
\hline Min temperature $\left({ }^{\circ} \mathrm{C}\right)$ & 7.3 & $7.3[6.5,8.1]$ & $8.2[7.3,9.1]$ & $9.1[7.9,10.3]$ \\
Max temperature $\left({ }^{\circ} \mathrm{C}\right)$ & 20.0 & $20.5[19.7,21.3]$ & $21.6[20.7,22.5]$ & $22.6[21.6,23.6]$ \\
Precipitation $(\mathrm{mm})$ & 105.6 & $123.1[103.5,142.7]$ & $110.6[93.8,127.4]$ & $94.1[77.0,111.2]$ \\
Relative humidity $(\%)$ & 76.3 & $76.3[74.1,78.5]$ & $75.0[72.8,77.2]$ & $74.2[72.0,76.4]$ \\
Cloudiness $(\%)$ & 48.6 & $42.5[41.4,43.6]$ & $40.8[39.2,42.4]$ & $39.5[38.1,40.9]$ \\
Wind speed $\left(\mathrm{m} \mathrm{s}^{-1}\right)$ & 3.1 & $2.9[2.8,3.0]$ & $2.9[2.8,3.0]$ & $2.9[2.7,3.1]$ \\
\hline
\end{tabular}

summer winds in Mallorca are produced by a recurrent and well-defined sea breeze (Ramis and Romero 1995), but these small-scale wind regimes are beyond the current model resolutions. Consequently, the projected frequency of calms or light winds in the warm season might arguably be positively biased. Figure 10f confirms moderate decreases of strong winds for all seasons, except for winter.

\section{Conclusions and further remarks}

A study of the effects of climate change over the SPdP has been carried out in association with the Consortium of Platja de Palma. Key issues for the consortium are sustainability, climate and global change, and social and residential cohesion. Therefore, the assessment of climate change over this geographical setting has turned one of the most important concerns to address its renovation and appropriateness to the social, economic, and environmental demands of the twenty-first century. To this aim, observed and simulated daily series of minimum and maximum temperatures, precipitation, relative humidity, cloud cover, and wind speed have been analyzed. For the future projections, multiple RCMs have been used to cope with the uncertainties arising from model errors and their boundary conditions.

To exploit this regional database correctly at such local scales, we have applied a novel quantile-quantile adjustment to individual RCM daily outputs. The skill of the statistical correction has been checked, first by means of a validation test, and then by means of a robustness test. The verification process has allowed access to the benefits of adopting such an approach. Results show an overall improvement in reproducing the present climate baseline (i.e., 1994-2008) when using calibrated series instead of raw RCM outputs. Nevertheless, the statistical correction does not result in such a clear improvement for the precipitation, as revealed by the RMSE; however, this fact can be ascribed to its inherent high variability-particularly in Mallorca, where the strong dependence of rainfall amounts on local topography is poorly represented at current RCM resolution - and the occurrence of extreme values. Furthermore, the temporal limitation of the observed control period could entail that the entire rainfall distribution might not be well sampled over 15-yr periods. If observed daily series were long enough, then it might be possible to better encompass these biases. Moreover, a bootstrap test has demonstrated the robustness of the adjustment to the selection of the training set. The method is rather insensitive to the particular sampling used to characterize the control climate.

In addition, we have carried out some additional tests. First, annual and seasonal adjustments have been compared to evaluate the benefits of using seasonal instead of annual correction functions. No clear benefits have been obtained by applying a seasonal rather than an annual calibration for the SPdP. The annual adjustment is applied locally for the entire CDFs and, as the annual distributions of daily variables contain the seasonal cycles, the adjustment implicitly accounts for biases that could depend on each season. Furthermore, the aforementioned temporal limitation is more accentuated by conducting seasonal-dependent correction functions for calibration purposes. It would be highly recommended to further explore these issues when longer temporal daily data series are available. Similarities and differences between the SPdP and WB quantilequantile adjustments have also been evaluated. When changes in the mean state, variability, and shape among

TABLE 9. As in Table 7, but for the multimodel summer mean regimes of the climatic variables.

\begin{tabular}{lcccc}
\hline \multicolumn{1}{c}{ Summer } & Present & Early & Middle & Late \\
\hline Min temperature $\left({ }^{\circ} \mathrm{C}\right)$ & 16.8 & $17.6[17.1,18.1]$ & $18.9[18.1,19.7]$ & $20.4[19.4,21.4]$ \\
Max temperature $\left({ }^{\circ} \mathrm{C}\right)$ & 29.8 & $30.9[30.4,31.4]$ & $32.3[31.5,33.1]$ & $33.7[32.8,34.6]$ \\
Precipitation $(\mathrm{mm})$ & 58.6 & $43.8[19.2,68.4]$ & $37.1[11.7,62.5]$ & $28.4[3.3,53.5]$ \\
Relative humidity $(\%)$ & 71.4 & $69.9[64.7,75.1]$ & $68.0[62.8,73.2]$ & $66.3[60.9,71.7]$ \\
Cloudiness $(\%)$ & 30.0 & $28.3[24.9,31.7]$ & $27.0[23.4,30.6]$ & $25.6[21.4,29.8]$ \\
Wind speed $\left(\mathrm{m} \mathrm{s}^{-1}\right)$ & 3.0 & $2.1[1.9,2.3]$ & $2.1[1.9,2.3]$ & $2.1[1.9,2.3]$ \\
\hline
\end{tabular}


TABLE 10. As in Table 7, but for the multimodel autumn mean regimes of the climatic variables.

\begin{tabular}{lcccc}
\hline \hline \multicolumn{1}{c}{ Autumn } & Present & Early & Middle & Late \\
\hline Min temperature $\left({ }^{\circ} \mathrm{C}\right)$ & 11.9 & $13.0[12.3,13.7]$ & $14.3[13.5,15.1]$ & $15.4[14.4,16.4]$ \\
Max temperature $\left({ }^{\circ} \mathrm{C}\right)$ & 23.4 & $23.0[23.5,24.9]$ & $24.1[24.7,26.3]$ & $25.3[25.5,27.7]$ \\
Precipitation $(\mathrm{mm})$ & 176.2 & $212.3[185.1,239.5]$ & $182.9[146.3,219.5]$ & $185.7[157.0,214.4]$ \\
Relative humidity $(\%)$ & 79.4 & $77.9[77.0,78.8]$ & $77.1[76.2,78.0]$ & $76.7[75.9,77.5]$ \\
Cloudiness $(\%)$ & 46.3 & $44.7[43.2,46.2]$ & $43.2[41.5,44.9]$ & $42.1[40.7,43.5]$ \\
Wind speed $\left(\mathrm{m} \mathrm{s}^{-1}\right)$ & 2.7 & $2.6[2.5,2.7]$ & $2.6[2.5,2.7]$ & $2.5[2.4,2.6]$ \\
\hline
\end{tabular}

observed and simulated CDFs are relatively small, both methods yield almost identical results. However, when these changes are not so small or the distributions of the daily variables are not so well behaved, clear differences arise between both methods and most variables are better corrected by the SPdP adjustment.

Once RCM daily series were calibrated to the SPdP, we analyzed the projected climate change signal. The results have been discussed in terms of changes in the annual and seasonal mean regimes, as well as in terms of changes in the frequency of the extreme events. Therefore, the impacts of climate change can be assessed to guide the planning and exploitation of the urban, environmental, and tourist activities in the area. The projections have revealed important changes in the temperature regimes that should help local authorities to activate contingency plans. It would be highly recommended to take precautionary measures before the projected increase in the frequency of extreme hot days affect the SPdP in summertime. Note that the $2003 \mathrm{Eu}$ ropean heat wave led to severe health crises in several countries, resulting in more than 52000 fatalities (Larsen 2010). However, it must not be forgotten that the number of annual fatalities due to extreme cold days in central and northern Europe is currently much higher than those produced by extreme hot days.

The changes found in the rainfall regimes, with an increased scarcity of rainfall amounts especially in the warm season, should also imply a future update of the current water management plans. The projected rise in the frequency of both daily extreme-weak and intenserainfalls will be a challenging task for hydrologic management as well. Intense precipitations are rather inefficient for increasing the inland water storage. Most of the heavy rainfall runs off and is therefore carried out to the sea by the local drainage. Furthermore, the possible growth in the socioeconomic losses should be considered mainly related to flash flooding or to longer drought periods- the (a)

Changes in seasonal low extreme regimes for minimum temperature

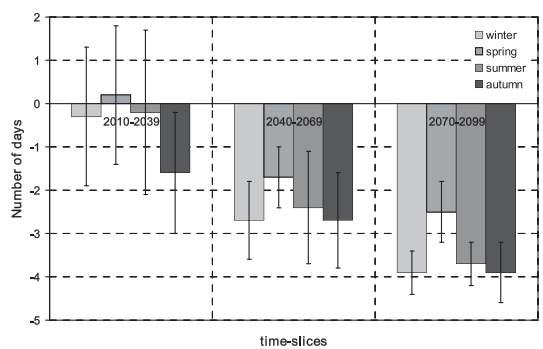

(d) Changes in seasonal low extreme regime for relative humidity

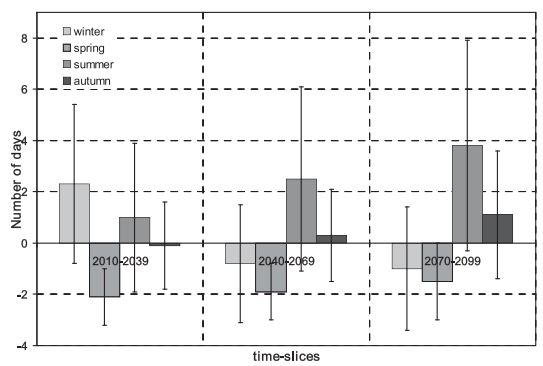

(b) Changes in seasonal low extreme regime for maximum
tem perature

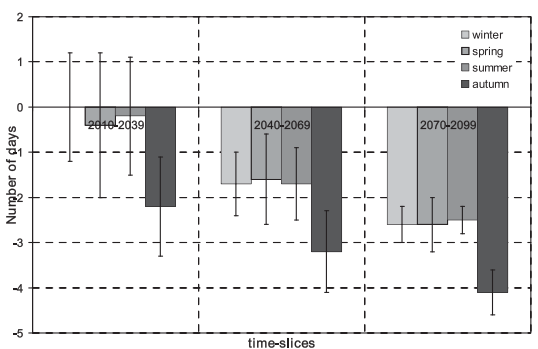

(e) Changes in seasonal low extreme regime for cloudiness

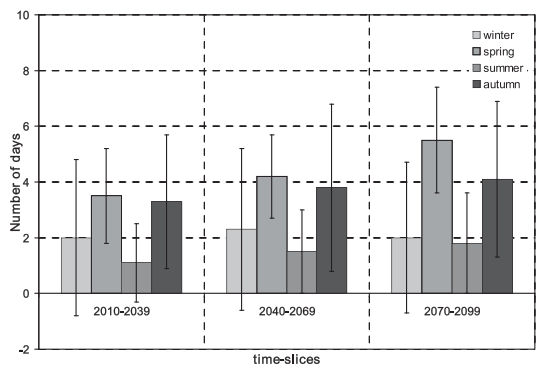

(c) Changes in seasonal low extreme regime for precipitation

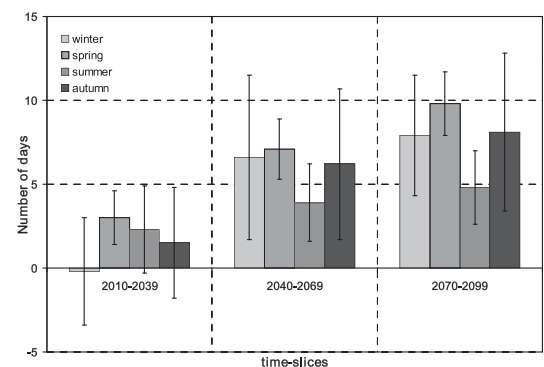

(f) Changes in seasonal low extreme regime for wind speed

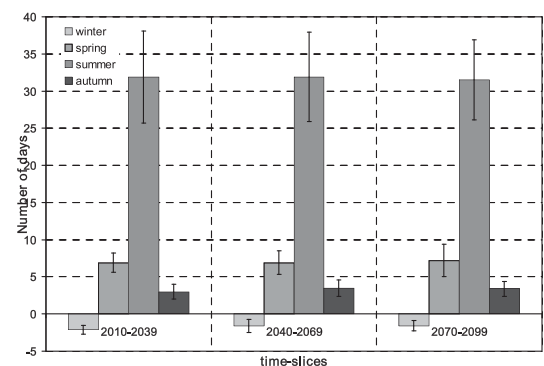

FIG. 9. Number of low extreme days per season for the future time slices. Thresholds used to define these extremes are obtained for the present period and remain unchanged for the future time slices. It is worth noting that the changes in the number of days are computed as the difference among the projected and observed extreme days. Multimodel means and their standard deviation are shown. 
(a) Changes in seasonal high extreme regime for minimum temperature

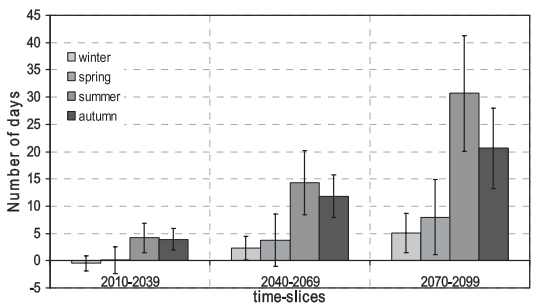

(d) Changes in seasonal high extreme regime for relative humidity

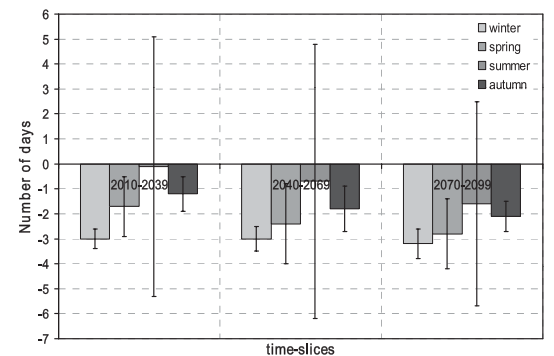

(b) Changes in seasonal high extreme regime for maximum temperature

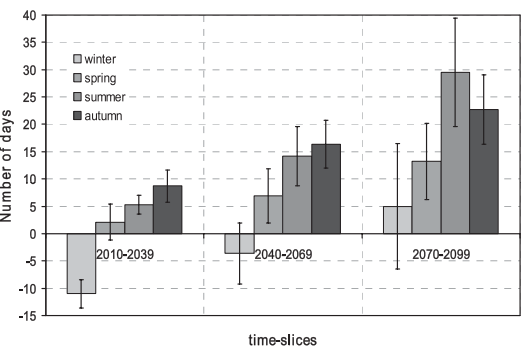

(e) Changes in seasonal high extreme regime for cloudiness

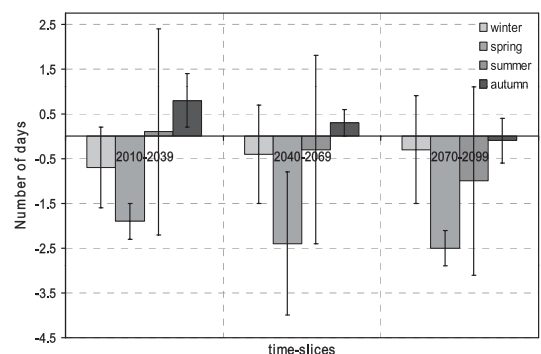

(c) Changes in seasonal high extreme regime for precipitation

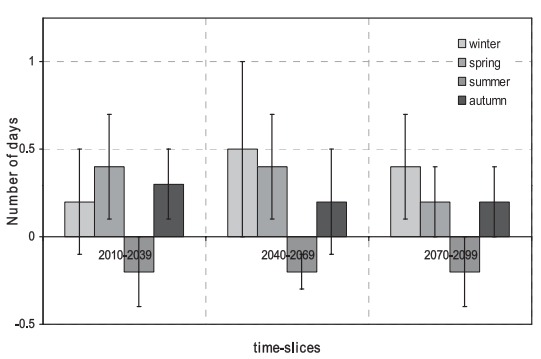

(f) Changes in seasonal high extreme regime for wind speed

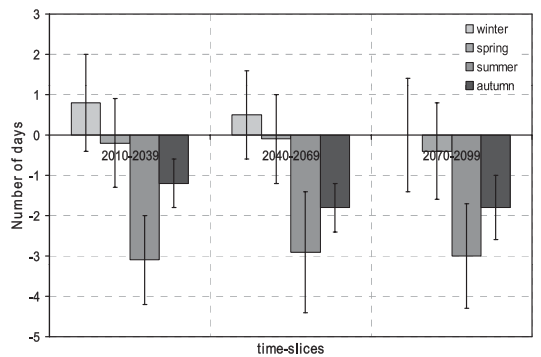

FIG. 10. As in Fig. 9, but for the high extreme days per season.

2003 European heat wave combined with drought caused a crop shortfall in southern Europe. Changes found for the remaining climatic variables (relative humidity, cloud cover, and wind speed) also can be taken into consideration when designing urban infrastructure. As an example, shifts in the relative humidity regimes appear to indicate a drying of the environment, and hence these effects should be included in the ecological management of the area apart from more obvious effects associated with temperature and precipitation changes.

Finally, it is important to mention a potential extension of the current research by exploring the future evolution of tourism - the most important socioeconomic asset of Platja de Palma-through the formulation of appropriate tourism climate indices. Well-founded tourism climate indices must take into account, beyond a simple analysis of meteorological parameters, an integrated human body-atmosphere energy balance model to calculate the thermal sensation and even aesthetic aspects, such as cloud cover, or physical facets, such as wind intensity and rain occurrence. Some examples of different tourism climate indices and their applications have been used, for example, by Mieczkowski (1985), Becker (1998), Harlfinger (1991), Morgan et al. (2000), Amelung and Viner (2006), and De Freitas et al. (2008). Integration of these tourism climate indices within the climatic scenarios derived from RCMs appear to be of maximum interest for subsequent studies dealing with the future evolution of tourism in the SPdP, the Balearic Islands, and the whole Mediterranean region in general.
Acknowledgments. The authors express their thanks and appreciation to Dr. Charles A. Doswell III, visiting professor at UIB, for his valuable comments and suggestions on this work. Dr. Robert Wood, editor of Journal of Climate, and the anonymous reviewers are deeply acknowledged for their valuable comments, which helped to improve the quality of this manuscript. The Spanish Agency of Meteorology (AEMET) is also acknowledged for providing the automatic weather station data. This work has been sponsored by El Consorci de la Platja de Palma, with funds provided by the Balearic Islands and the Spanish state governments through the Institut Mediterrani d'Estudis Avançats (IMEDEA; CSIC-UIB); by the MEDICANES Spanish project (CGL2008-01271/ CLI), which is partially supported with FEDER funds; and by ESTCENA project (200800050084078), a strategic action from Plan Nacional de I+D+i 2008-11 funded by the Ministerio de Medio Ambiente y Medio Rural y Marino. The authors acknowledge the ENSEMBLES project, funded by the European Commission's Sixth Framework Programme, through Contract GOCE-CT2003-505539.

\section{APPENDIX}

\section{Theoretical Basis and Underlying Hypotheses of the Quantile-Quantile Adjustment}

The quantile-quantile adjustment is rooted in the fact that the projected climate $\left(p_{i}\right)$ must depend on the 
observed climate $\left(o_{i}\right)$ and on the model-simulated change in terms of both climatic mean $(\bar{\Delta})$ and specific distribution $\left(\Delta_{i}^{\prime}\right)$, where $i$ indicates the $i$ th quantile of the distributions as shown:

$$
p_{i}=\mathbb{F}\left(o_{i}, \bar{\Delta}, \Delta_{i}^{\prime}\right) .
$$

A first-order approximation to $\mathbb{F}$ is

$$
p_{i}=a+b o_{i}+g \bar{\Delta}+f \Delta_{i}^{\prime},
$$

where $a, b, g$, and $f$ are parameters to be determined from desired properties of the adjustment method. In particular, the following constraints (denoted as C) are formulated:

C.1: If no climate change was simulated by the RCM, then the projected distribution must obviously converge to the observed climatic distribution as shown:

$$
\text { If }\left\{\begin{array}{rl}
\bar{\Delta} & =0 \\
\Delta_{i}^{\prime} & =0
\end{array} \Rightarrow p_{i}=o_{i} \quad \forall i .\right.
$$

The unique set of $a, b$ constants in Eq. (A2) that satisfies this condition for all $i$ is

$$
\left\{\begin{array}{l}
a=0 \\
b=1
\end{array}\right. \text {. }
$$

Now, since the mean of Eq. (4) is zero, the mean of the projected distribution [Eq. (A2)] becomes

$$
\bar{P}=\bar{O}+g \bar{\Delta}=\bar{O}+g\left(\overline{S_{f}}-\overline{S_{c}}\right)
$$

and the deviation of each quantile is

$$
p_{i}^{\prime}=p_{i}-\bar{P}=o_{i}^{\prime}+f \Delta_{i}^{\prime}=o_{i}^{\prime}+f\left(s_{\mathrm{fi}}^{\prime}-s_{\mathrm{ci}}^{\prime}\right) .
$$

C.2a: For maximum and minimum temperatures, we follow the standard assumption that the simulated shift in mean climate is a credible quantity of RCMs. Thus, this shift must be preserved in the projected climate as shown:

$$
\bar{P}-\bar{O}=\overline{S_{f}}-\overline{S_{c}},
$$

yielding $g=1$ from Eq. (A3)

C.2b: For the remaining atmospheric variables, it is the relative change in mean climate that will be preserved in the projected future. This is also a common hypothesis made in climate change studies,

$$
\frac{\bar{P}}{\bar{O}}=\frac{\overline{S_{f}}}{\overline{S_{c}}}
$$

After substitution of $\bar{P}$ from the last equation into Eq. (A3), we obtain

$$
g=\frac{\bar{O}}{\overline{S_{c}}}
$$

C.3: Our last hypothesis, applied to the whole set of atmospheric variables, deals with the ability of RCMs to simulate the changes in variability. We assume that models can reasonably capture the relative change in variability; thus, the same relative change will be applied to the projected climate as shown:

$$
\frac{p_{i}^{\prime}-o_{i}^{\prime}}{\sigma_{O}}=\frac{s_{\mathrm{fi}}^{\prime}-s_{\mathrm{ci}}^{\prime}}{\sigma_{S_{c}}} .
$$

This condition is less restrictive than those used in previous procedures (e.g., the "delta" or the unbiasing methods). Recall that the former method considers that the variability in the future scenario remains unchanged, while the latter states that the RCM variability is perfect.

The combination of Eqs. (A4) and (A8) yields

$$
f=\frac{\sigma_{O}}{\sigma_{S_{c}}} .
$$

Note that the $g$ and $f$ parameters emerging from hypotheses C.2a, C.2b, and C.3 make the quantilequantile adjustment fully scale invariant for the whole set of atmospheric variables. That is, the adjustment results are invariant under any linear transformation (e.g., units change transformations, such as from $\mathrm{K}$ to ${ }^{\circ} \mathrm{C}$ for temperatures, from $\mathrm{mm}$ to in. for precipitation, from $\mathrm{m} \mathrm{s}^{-1}$ to $\mathrm{kt}$ for wind).

\section{REFERENCES}

Akima, H., 1978: A method of bivariate interpolation and smooth surface fitting for irregularly distributed data points. $A C M$ Trans. Math. Software, 4, 148-164.

_- 1996: Algorithm 761: Scattered-data surface fitting that has the accuracy of a cubic polynomial. ACM Trans. Math. Software, 22, 362-371.

Alpert, P., and Coauthors, 2002: The paradoxical increase of Mediterranean extreme daily rainfall in spite of decrease in total values. Geophys. Res. Lett., 29, 1536, doi:10.1029/2001GL013554.

Amelung, B., and D. Viner, 2006: Mediterranean tourism: Exploring the future with the tourism climatic index. J. Sustainable Tourism, 14, 349-366.

Amengual, A., R. Romero, V. Homar, C. Ramis, and S. Alonso, 2007: Impact of the lateral boundary conditions resolution on dynamical downscaling of precipitation in Mediterranean Spain. Climate Dyn., 29, 487-499, doi:10.1007/s00382-007-0242-0. 
and S. Alonso, 2008: Hydrometeorological ensemble simulations of flood events over a small basin of Mallorca Island, Spain. Quart. J. Roy. Meteor. Soc., 134, 1221-1242, doi:10.1002/qj.291.

Beck, A., B. Ahrens, and K. Stadlbacher, 2004: Impact of nesting strategies in dynamical downscaling of reanalysis data. Geophys. Res. Lett., 31, L19101, doi:10.1029/2004GL020115.

Becker, S., 1998: Beach comfort index: A new approach to evaluate the thermal conditions of beach holiday resort using a South Africa example. GeoJournal, 44, 297-307.

Boé, J., L. Terray, F. Habets, and E. Martin, 2007: Statistical and dynamical downscaling of the Seine basin climate for hydrometeorological studies. Int. J. Climatol., 27, 1643-1655.

Christensen, J. H., and O. B. Christensen, 2003: Severe summertime flooding in Europe. Nature, 421, 805-806.

De Freitas, C. R., D. Scott, and G. McBoyle, 2008: A second generation climate index for tourism (CIT): Specification and validation. Int. J. Biometeor., 52, 399-407.

Denis, B., R. Laprise, D. Caya, and J. Coté, 2002: Downscaling ability of one-way nested regional climate models: The BigBrother experiment. Climate Dyn., 18, 627-646.

Déqué, M., 2007: Frequency of precipitation and temperature extremes over France in an anthropogenic scenario: Model results and statistical correction according to observed values Global Planet. Change, 57, 16-26.

Frei, C., R. Schöll, S. Fukutome, J. Schmidli, and P. L. Vidale, 2006: Future change of precipitation extremes in Europe: Intercomparison of scenarios from regional climate models. J. Geophys. Res., 111, D06105, doi:10.1029/2005JD005965.

Giorgi, F., and L. O. Mearns, 1999: Introduction to special section: Regional climate modeling revisited. J. Geophys. Res., 104 (D6), 6335-6352.

_- X. Bi, and J. Pal, 2004: Mean interannual and trends in a regional climate change experiment over Europe. II: Climate change scenarios (2071-2100). Climate Dyn., 23, 839-858.

Gual, M., J. Perelló, and C. Ramis, 2002: La isla de calor urbana en Palma de Mallorca. Rev. Esp. Fis., 16, 39-43.

Guijarro, J. A., 1986: Contribución a la bioclimatología de Baleares. Ph.D. thesis, Universitat de les Illes Balears, 225 pp.

Harlfinger, O., 1991: Holiday biometeorology: A study of Palma de Mallorca, Spain. GeoJournal, 25, 377-381.

Hewitt, C. D., 2004: Ensembles-based predictions of climate changes and their impacts. Eos, Trans. Amer. Geophys. Union, 85, doi:10.1029/2004EO520005.

Homar, V., C. Ramis, R. Romero, and S. Alonso, 2010: Recent trends in temperature and precipitation over the Balearic Islands (Spain). Climatic Change, 98, 199-211.

Huntington, T. G., 2006: Evidence for intensification of the global water cycle: Review and synthesis. J. Hydrol., 319, 83-95.

INE, cited 2010: Encuesta de la ocupación hotelera. [Available online at http://www.ine.es.]
Kjellström, E., 2004: Recent and future signatures of climate change in Europe. Ambio, 23, 193-198.

Larsen, J., cited 2010: Setting the record straight: More than 52,000 Europeans died from heat in summer 2003. [Available online at http://www.earth-policy.org/index.php?/plan_b_updates/ 2006/update56.]

Leckebusch, G. C., B. Koffi, U. Ulbrich, J. G. Pinto, T. Spangehl, and S. Zacharias, 2006: Analysis of frequency and intensity of European winter storm events from a multi-model perspective, at synoptic and regional scales. Climate Res., 31, 59-74.

Llasat, M. C., 2001: An objective classification of rainfall intensity in the northeast of Spain. Int. J. Climatol., 21, 1385-1400.

Mieczkowski, Z., 1985: The tourism climatic index: A method of evaluating world climates for tourism. Can. Geogr., 29, 220-233.

Morgan, R., E. Gatell, R. Junyent, A. Micallef, E. Özhan, and A. Williams, 2000: An improved user-based beach climate index. J. Coastal Conserv., 6, 41-50.

Nakicenovic, N., and R. Swart, Eds., 2000: Special Report on Emissions Scenarios. Cambridge University Press, 599 pp.

Räisänen, J., and Coauthors, 2004: European climate in the late twenty-first century: Regional simulations with two driving global models and two forcing scenarios. Climate Dyn., 22, 13-31.

Ramis, C., and R. Romero, 1995: A first numerical simulation of the development and structure of the sea breeze in the island of Mallorca. Ann. Geophys., 13, 981-994.

Reichle, R. H., and R. D. Koster, 2004: Bias reduction in short records of satellite soil moisture. Geophys. Res. Lett., 31, L19501, doi:10.1029/2004GL020938.

Romero, R., G. Sumner, C. Ramis, and A. Genovés, 1999: A classification of the atmospheric circulation patterns producing significant daily rainfall in the Spanish Mediterranean area. Int. J. Climatol., 19, 765-785.

Semenov, V. A., and L. Bengtsson, 2002: Secular trends in daily precipitation characteristics: Greenhouse gas simulation with a coupled AOGCM. Climate Dyn., 19, 123-140.

Smith, T. M., R. W. Reynolds, T. C. Peterson, and J. Lawrimore, 2008: Improvements to NOAA's historical merged land-ocean surface temperature analysis (1880-2006). J. Climate, 21, 2283-2293.

Solomon, S., D. Qin, M. Manning, M. Marquis, K. Averyt, M. M. B. Tignor, H. L. Miller Jr., and Z. Chen, Eds., 2007: Climate Change 2007: The Physical Science Basis. Cambridge University Press, 996 pp.

Tudurí, E., and C. Ramis, 1997: The environments of significant convective events in the western Mediterranean. Wea. Forecasting, 12, 294-306.

Voss, R., W. May, and E. Roeckner, 2002: Enhanced resolution modelling study on anthropogenic climate change: Changes in extremes of the hydrological cycle. Int. J. Climatol., 22, 755-777.

Wood, A., L. R. Leung, V. Sridhar, and D. P. Lettenmaier, 2004: Hydrologic implications of dynamical and statistical approaches to downscaling climate outputs. Climatic Change, 62, 189-216. 